\title{
A Quantitative Analysis of Presynaptic Calcium Dynamics That Contribute to Short-Term Enhancement
}

\author{
D. W. Tank, ${ }^{1}$ W. G. Regehr, ${ }^{1, a}$ and K. R. Delaney ${ }^{1,2, b}$ \\ ${ }^{1}$ Biological Computation Research Department, AT\&T Bell Laboratories, Murray Hill, New Jersey 07974, and \\ ${ }^{2}$ Department of Physiology and Biophysics, New York University, New York
}

\begin{abstract}
Augmentation and posttetanic potentiation-two forms of short-term synaptic enhancement produced by repetitive presynaptic action potentials-are dependent on the buildup and decay of nerve terminal residual calcium that occurs on the seconds to minutes time scale. With the goal of providing a quantitative understanding of these kinetics, we measured the buildup and decay of calcium ions in nerve terminals at the crayfish neuromuscular junction under a variety of intracellular buffer conditions and stimulation paradigms. The calcium extrusion process in the terminals was characterized by analysis of calcium levels reached during long stimulus trains as a function of action potential frequency. The extrusion was linearly dependent on the free calcium ion concentration. Using this result, we developed a mathematical model and computer simulation of the residual calcium kinetics. The model demonstrates the experimentally observed dependence of decay rate on exogenous calcium buffer concentration, and can be explicitly solved to provide an expression for the limiting exponential time course of calcium decay following trains in terms of calcium buffer and extrusion characteristics. Methods to determine the calcium influx per action potential, characteristics of endogenous buffer, and the rate of calcium extrusion are suggested by our analysis and demonstrated experimentally.
\end{abstract}

[Key words: modeling, simulation, augmentation, posttetanic potentiation, crayfish neuromuscular junction, calcium buffering, calcium extrusion, fura-2]

The calcium influx associated with action potential invasion of a presynaptic nerve terminal produces brief (milliseconds), highconcentration $(>100 \mu \mathrm{M}$ ) gradients of calcium ions near open calcium channels that trigger neurotransmitter release (Augustine and Neher, 1992; Llinas et al., 1992). These gradients rapidly dissipate by diffusion and binding to intracellular calcium buffers but add a calcium load to a more spatially extended pool of calcium, termed residual calcium. Residual calcium has a much slower dynamics, typically on the hundreds of milliseconds to seconds time scale and it plays a central role in the

\footnotetext{
Received June 29, 1995; revised July 28, 1995; accepted Aug. 2, 1995.

K.R.D. was the recipient of an MRC Canada Fellowship.

Correspondence should be addressed to David W. Tank, Room 1C427, ATT

Bell Laboratories, 600 Mountain Avenue, Murray Hill, NJ 07974.

"Present address: Department of Neurobiology, Harvard Medical School, Boston, MA.

'Present address: Department of Biological Sciences, Simon Frasier University, Vancouver, B.C. Canada.

Copyright $\mathcal{C} 1995$ Society for Neuroscience $0270-6474 / 95 / 157940-13 \$ 05.00 / 0$
}

production of short-term synaptic enhancement such as augmentation and posttetanic potentiation (Zucker et al., 1991). The slower dynamics associated with presynaptic residual frec calcium ion concentration $\left(\left[\mathrm{Ca}^{2+}\right]\right.$ ) can be measured under conditions of normal synaptic transmission (Delaney et al., 1989, 1991; Regehr and Tank, 1991; Swandula et al., 1991; Zucker et al., 1991; Regehr et al., 1993) using high-affinity fluorescent calcium ion indicator molecules such as fura-2 (Grynkiewicz et al., 1985). Several examples of the buildup and decay of $\left[\mathrm{Ca}^{2+}\right]$ determined from fura- 2 measurements in presynaptic terminals of the crayfish neuromuscular junction are shown in Figure 1.

When a train of action potentials is produced in the axon leading to the presynaptic terminal, the intraterminal $\left[\mathrm{Ca}^{2+}\right]$ rises. For long-duration action potential trains under $25 \mathrm{~Hz},\left[\mathrm{Ca}^{2+}\right]$ reaches a steady-state level during stimulation that is dependent on the stimulation frequency and decays following termination of the action potential train. When very low concentrations of fura- 2 are used, $\left[\mathrm{Ca}^{2+}\right]$ decays can be approximated, for the time period beginning about $1 \mathrm{sec}$ following termination, by an exponential decay with a time constant of approximately $6 \mathrm{sec}$ at $20^{\circ} \mathrm{C}$. This decay parallels a concomitant decay in a component of enhanced synaptic connection strength called augmentation. During augmentation, the degree of synaptic enhancement is linearly related to the level of increased $\left[\mathrm{Ca}^{2+}\right]$ (Delaney and Tank, 1994). As shown in Figure 1, $\left[\mathrm{Ca}^{2+}\right]$ decay kinetics can be profoundly slowed when exogenous calcium buffers are added to the cytoplasm. A concomitant slowing down of augmentation is observed, directly demonstrating the importance of calcium handling in the kinetics of short-term synaptic enhancement (Swandula et al., 1991; Delaney and Tank, 1994).

To understand the biophysical processes that control slow $\left[\mathrm{Ca}^{2+}\right]$ kinetics, we have measured and analyzed $\left[\mathrm{Ca}^{2+}\right]$ changes in crayfish presynaptic terminals under different conditions of exogenous calcium buffers and stimulation trains. We also developed a single compartment $\left[\mathrm{Ca}^{2+}\right]$ dynamics model. Spatial gradients within the presynaptic nerve terminal we studied are expected to dissipate on a characteristic time scale for diffusion given by

$$
\Delta t=\frac{(\text { radius })^{2}}{6 D} \approx 0.1 \mathrm{sec}
$$

for an intracellular $\left[\mathrm{Ca}^{2+}\right]$ diffusion coefficient of $\mathrm{D}=10^{-7} \mathrm{~cm}^{2} /$ sec and radius $=2.5 \mu \mathrm{m}$. During the seconds-long $\left[\mathrm{Ca}^{2+}\right]$ decay following a train of action potentials, spatial gradients of $\left[\mathrm{Ca}^{2+}\right]$ are small because the decay rate is long compared to this diffusion time scale. Our model assumes this spatial homogeneity, modeling intracellular space as a single compartment. $\left[\mathrm{Ca}^{2+}\right]$ 


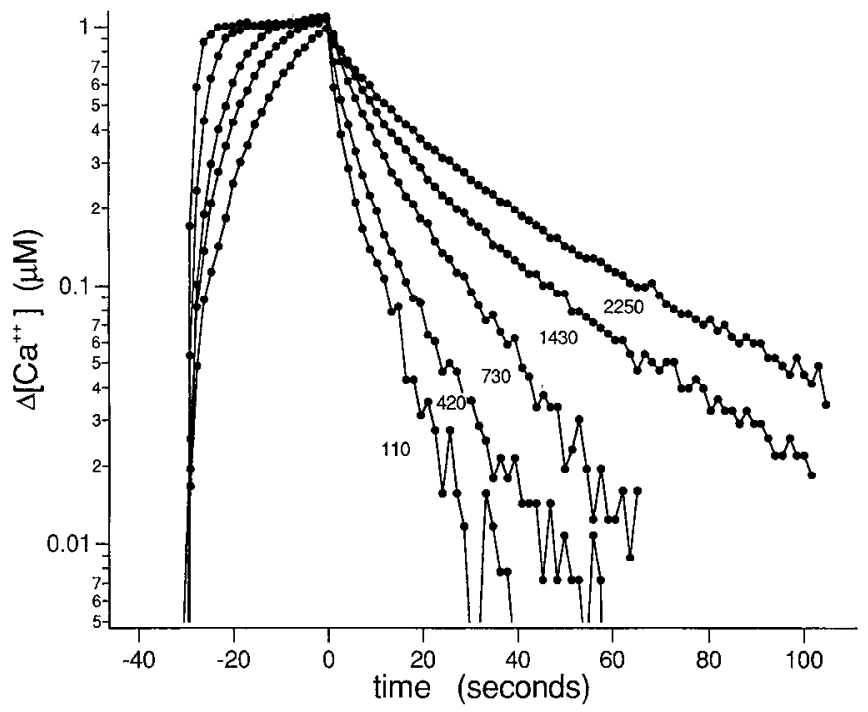

Figure 1. Semi-log plot of $\Delta\left[\mathrm{Ca}^{2+}\right]$ versus time for different estimated levels of intraterminal fura- 2 concentration. Each curve shows the buildup to a steady-state level of $\left[\mathrm{Ca}^{2+}\right]$ in a presynaptic terminal at the crayfish $\mathrm{nmj}$ in response to a stimulus train of action potentials at 25 $\mathrm{Hz}$. Increasing exogenous buffer concentration slows the buildup and decay kinetics but not the level reached during the plateau phase. $T=$ $18.5^{\circ} \mathrm{C}$. Estimated fura- 2 concentration (in $\mu \mathrm{M}$ ) is indicated by the number next to each curve.

kinetics in the cytoplasm are produced by binding to calcium buffers and calcium extrusion. We model these processes with differential equations that can be numerically integrated to simulate $\left[\mathrm{Ca}^{2+}\right]$ dynamics. In addition, the mathematical form of $\left[\mathrm{Ca}^{2+}\right]$ decay can be explicitly solved and its dependence on calcium buffers and extrusion mechanisms summarized in mathematical expressions.

In the following, we first describe several basic characteristics of $\left[\mathrm{Ca}^{2+}\right]$ buildup and decay in crayfish presynaptic nerve ter- minals. We then provide experimental evidence for a calcium extrusion rate that is first order in $\left[\mathrm{Ca}^{2+}\right]$. We use this dependence in numerical simulations of $\left[\mathrm{Ca}^{2+}\right]$ decay in a single compartment model of the presynaptic nerve terminal. The mathematical formulae that describe the decay are compared to experimentally measured decay curves and used to estimate buffer capacity and extrusion rate. Following these descriptions of modeling the decay process, we present a mathematical model of the slow buildup of presynaptic $\left[\mathrm{Ca}^{2+}\right]$ during action potential trains. We demonstrate how this latter model can be used to estimate the $\left[\mathrm{Ca}^{2+}\right]$ influx per action potential and extrusion rate Mathematical derivations are contained in Appendices A and B. A summary of symbol definitions we use is given in Table 1 .

Preliminary reports of these findings have been published (Delaney et al., 1990, 1991; Tank et al., 1991).

\section{Materials and Methods}

Microfuorometric fura-2 measurement of presynaptic $\left[\mathrm{Ca}^{2+}\right]$. Preparation of the crayfish opener muscle for microfluorometric measurements of $\left[\mathrm{Ca}^{2+}\right]$ in presynaptic nerve terminals has been described previously (Delaney et al., 1989, 1991). Experiments reported here were performed on terminals of the inhibitor axon, rather than the exciter axon, to avoid movement problems that would be caused by contraction of the muscle at high stimulation frequencies. Estimates of $\left[\mathrm{Ca}^{2+}\right]$ were computed from Eq. (5) of Grynkiewicz et al. (Grynkiewicz et al., 1985) using a fura-2 dissociation constant of $865 \mathrm{nM}$ for crayfish cytoplasm and a viscosity correction factor of 0.7 (Delaney et al., 1989). A Photometrics (Tucson, AZ) cooled charge-coupled device attached to a modified upright epi-fluorescence microscope (Zeiss UEM) was used to acquire images of the $340 \mathrm{~nm}(20 \mathrm{~nm}$ bandwidth) and $380 \mathrm{~nm}(13 \mathrm{~nm}$ bandwidth) excited fluorescence (emission filter: $510 \mathrm{~nm}, 80 \mathrm{~nm}$ bandwidth) from fura-2-filled presynaptic terminals from which ratiometric estimates of the intraterminal $\left[\mathrm{Ca}^{2+}\right]$ were made. Measurements of the ratios at saturated and zero $\left[\mathrm{Ca}^{2+}\right]$ necessary for calibration were obtained as described previously (Delaney et al., 1989). Image acquisition and analysis were controlled by a Mac IIfx computer.

In several experiments, the intracellular buffer concentration was systematically altered by fura- 2 . A quantity of fura- 2 was injected into the axon and then the injection current was turned off, allowing the bolus to diffuse into the terminals. Once the concentration of fura- 2 in the

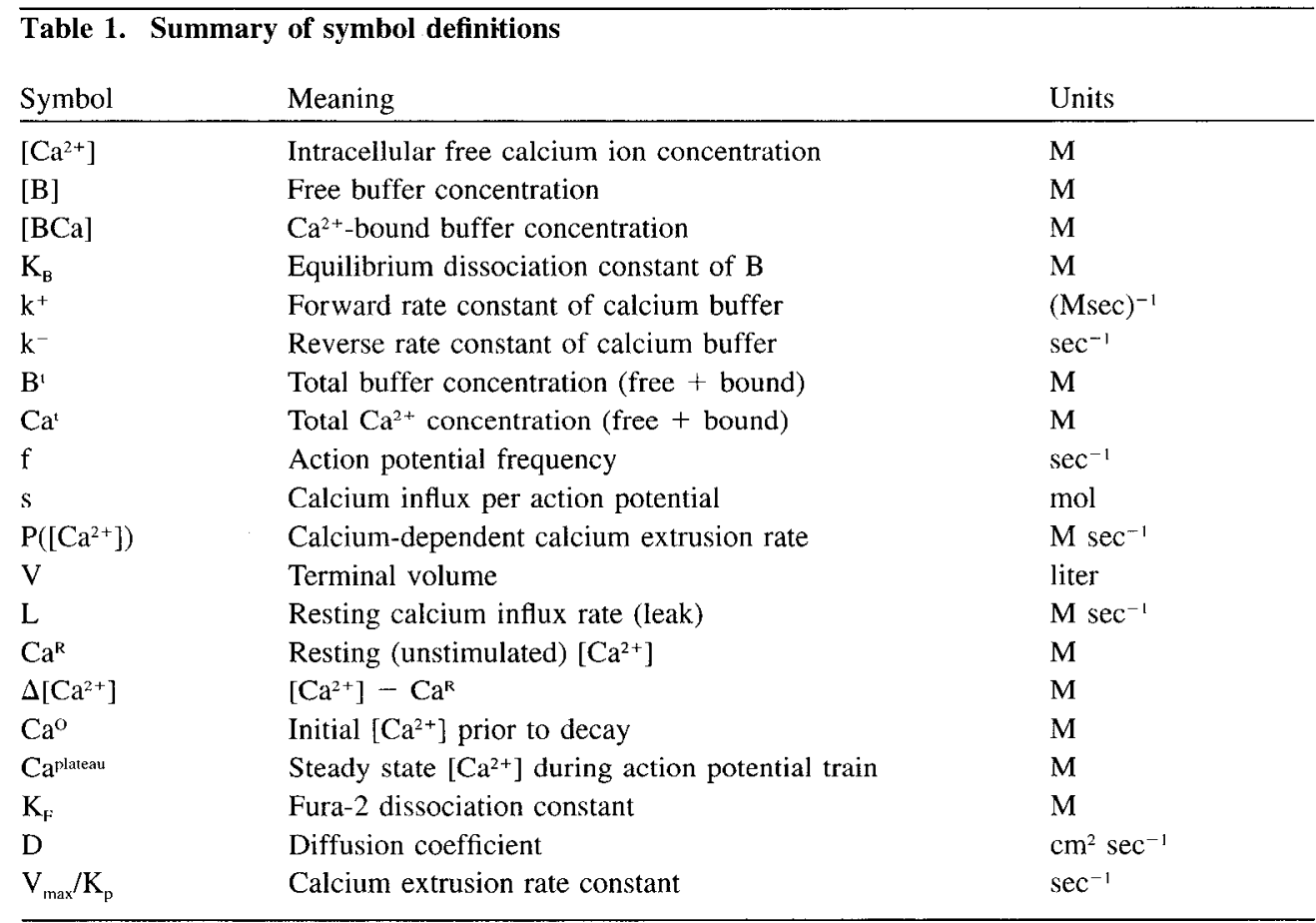




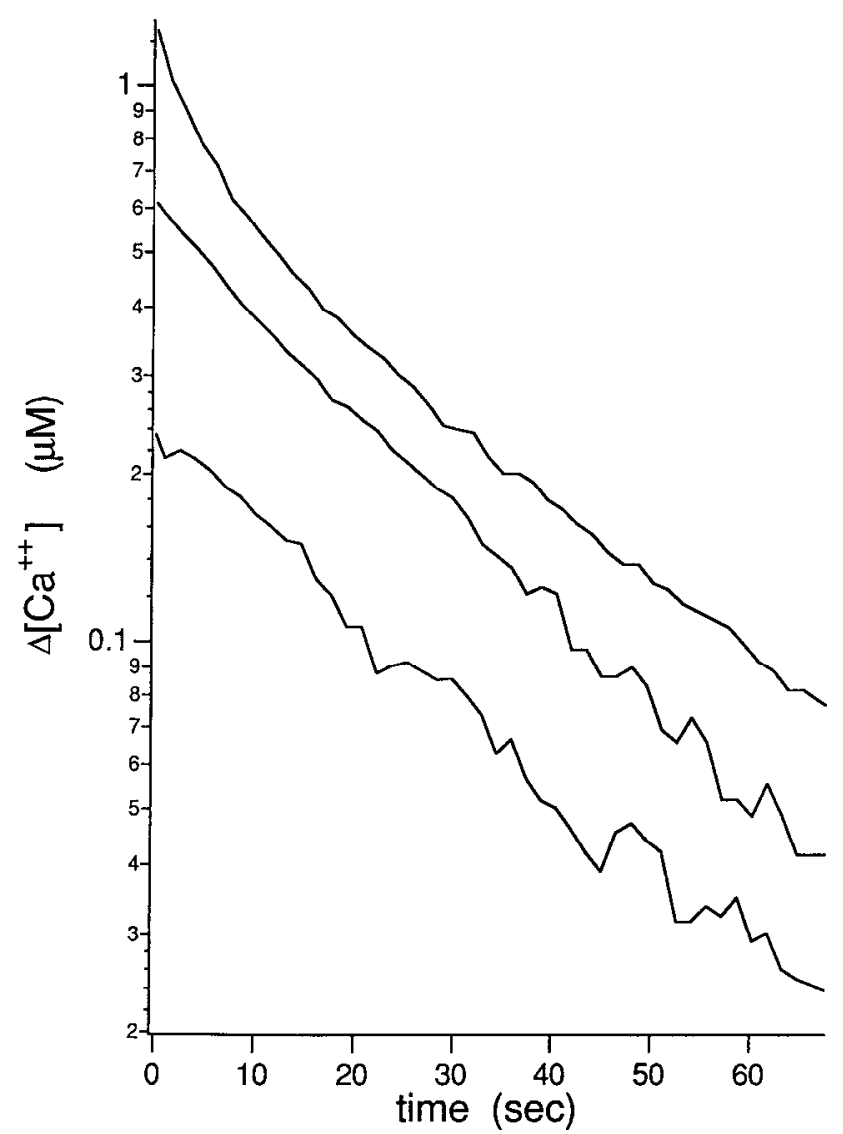

Figure 2. Semi-logarithmic plot of experimentally determined decays of $\Delta\left[\mathrm{Ca}^{2+}\right]$ in a presynaptic terminal under conditions where the dominant intracellular buffer is exogenously added fura-2. The decays are shown for initial $\left[\mathrm{Ca}^{2+}\right]$ levels produced following action potential trains lasting $10 \mathrm{sec}$ at $50 \mathrm{~Hz}$ (top), $15 \mathrm{sec}$ at $25 \mathrm{~Hz}$ (middle), and $12.5 \mathrm{sec}$ at $12.5 \mathrm{~Hz}$ (bottom). These initial levels approximately correspond to $\mathrm{Ca}^{0}=2 K_{F}, K_{F}$, and $0.5 K_{F}$. [fura-2] $\approx 900 \mu \mathrm{M}, T=18^{\circ} \mathrm{C}$.

imaged terminal had stabilized as determined from the stability of 380 $\mathrm{nm}$ excited fluorescence (typically 30-40 min), trains of action potentials of various lengths (typically $30 \mathrm{sec}$ ) and frequencies $(3.3-40 \mathrm{~Hz}$ ) were stimulated with a suction electrode on the leg nerve. $\left[\mathrm{Ca}^{2+}\right]$ buildup and decay experiments were performed at the stabilized fura- 2 concentration and then the injection continued until a maximum concentration of fura- 2 in the terminal, estimated to be $1-3 \mathrm{~mm}$, was produced. During and after stimulation with trains of action potentials, $100 \mathrm{msec}$ exposure time fluorescence image pairs $(340 \mathrm{~nm}$ and $380 \mathrm{~nm}$ excitation) were obtained every 0.52 or $1.52 \mathrm{sec}$, from which ratiometric mcasurements of $\left[\mathrm{Ca}^{2+}\right]$ were calculated. The exposures in an image pair were separated by $160 \mathrm{msec}$ and the midpoint between the acquisition of the images in a pair was used as the time of the $\left[\mathrm{Ca}^{2}{ }^{2}\right]$ measurement. Timing of image acquisition relative to nerve stimulation was achieved using a programmable digital stimulator (AMPI, Master-8).

Intraterminal fura- 2 concentrations were estimated from the intensity of fluorescence measured at $380 \mathrm{~nm}$ excitation at resting $\left[\mathrm{Ca}^{2+}\right](100-$ $150 \mathrm{~nm}$ ). Terminals were assumed to be ellipsoidal in shape, with a circular cross-section perpendicular to their long axis. The optical path length $(\Delta l)$ was thus given by the width of the terminal in a direction perpendicular to the supporting axon branches. For the short path length and low concentrations used in these experiments, the fluorescence intensity $F^{380}$ of the terminal is related to the fura- 2 concentration by the relationship

$$
F^{380}([\text { fura2 }])=f_{R}^{380} \Delta l[\text { fura2 }],
$$

where $\beta_{R}^{80}$ is the instrument-dependent fluorescence inlensity constant determined from calibration solutions of known [fura-2] and path length. Since the fluorescence produced by $380 \mathrm{~nm}$ excitation is also dependent on $\left[\mathrm{Ca}^{2+}\right]$, the following procedure was used to calculate the $f_{R}^{380}$ appropriate to the $\left[\mathrm{Ca}^{2+}\right]$ concentration at rest $\left(\mathrm{Ca}^{\mathrm{R}}\right)$. The amount of
$380 \mathrm{~nm}$ excited fluorescence produced by a known concentration of fura-2 was measured from a filled $20 \mu \mathrm{m}$ path-length microcapillary (Vitro Dynamics \#5002) for the solution used to compute $R_{\min }$ in the ratio calibration procedure (unbound fura-2) and for the solution used for $R_{\max }$ (bound fura-2). From the value produced with the $R_{\min }$ solution an $f_{\text {inin }}^{380}$ appropriate for unbound fura- 2 was calculated from an equation analogous to Eq. (2). Similarly, an $f_{\max }^{80}$ appropriate for bound fura-2 was calculated from the value produced with the $R_{\max }$ solution. The expected $f_{R}^{380}$ at the known resting $\left[\mathrm{Ca}^{2+}\right]$ level was then computed from the fraction of bound and unbound fura- 2 specified by the equilibrium equations:

$$
f_{R}^{380}=\left\{\frac{K_{F}}{\mathrm{Ca}^{R}+K_{F}}\right\} f_{\text {min }}^{380}+\left\{\frac{\mathrm{Ca}^{R}}{\mathrm{Ca}^{K}+K_{F}}\right\} f_{\max }^{380} .
$$

Resting $\left[\mathrm{Ca}^{2+}\right]$ levels in terminals were estimated to be $140 \mathrm{nM}$. At this concentration, $380 \mathrm{~nm}$ excited fura-2 fluorescence intensity is $87 \%$ of that observed at zero calcium. Slow drift in the intensity of the illumination system of the microscope was compensated for by measurement of the fluorescence produced by a fluorescent glass standard or by performing calibrations immediately following terminal imaging experiments.

Our ability to estimate the concentration of fura- 2 is limited by our estimate of the path length of the terminals, which is based upon the assumption that the cross-ection of small terminals is essentially circular and not flattened. Larger terminals appear to maintain the same proportion as small terminals, that is, the intensity of the fluorescence scales with the width in the $x-y$ plane. Serial reconstructions from electron micrographic sections (Jahromi and Atwood, 1974) suggest that small terminals are basically circular, but if a terminal we measure is somewhat flattened, we would overestimate the path length and, therefore, an underestimate of the fura- 2 concentration would result. We feel that our estimate of the concentration of fura- 2 is probably accurate to within $50 \%$.

$\left[\mathrm{Ca}^{2+}\right]$ decay simulations in a one compartment model. $\left[\mathrm{Ca}^{2+}\right]$ decay kinetics were numerically computed by integration of differential equations describing the calcium buffering, influx, and extrusion mechanisms. The approach was similar to that used in a previous investigation (Sala and Hernandez-Cruz, 1990). Simulations were performed on a single compartment model in which the terminal was considered as a spherical compartment of radius $2.5 \mu \mathrm{m}$. An initial $\left[\mathrm{Ca}^{2+}\right]$ level $\left(\mathrm{Ca}^{0}\right)$ was assumed and the initial concentrations of free buffer $[\mathrm{B}]$ and bound buffer [BCa] were determined from the equilibrium buffer expressions

$$
\begin{aligned}
{[\mathrm{BCa}] } & =\frac{\mathrm{B}^{\prime}\left[\mathrm{Ca}^{2+}\right]}{\left(\left[\mathrm{Ca}^{2+}\right]+K_{B}\right)}, \\
{[\mathrm{B}] } & =\frac{\mathrm{B}^{\prime} K_{B}}{\left(\left[\mathrm{Ca}^{2+}\right]+K_{B}\right)},
\end{aligned}
$$

using $\left[\mathrm{Ca}^{2+}\right]=\mathrm{Ca}^{0}$, where $\mathrm{B}^{t}=[\mathrm{B}]+[\mathrm{BCa}]$. The time evolution of the system was then determined by Euler integration of the equations

$$
\begin{aligned}
\frac{d\left[\mathrm{Ca}^{2+}\right]}{d t} & =k^{-}[\mathrm{BCa}]-k^{+}[\mathrm{B}]\left[\mathrm{Ca}^{2+}\right]+\mathrm{L}-\mathrm{P}\left(\left[\mathrm{Ca}^{2+}\right]\right), \\
\frac{d[\mathrm{BCa}]}{d t} & =-k^{-}[\mathrm{BCa}]+k^{+}[\mathrm{B}]\left[\mathrm{Ca}^{2+}\right] \\
\frac{d[\mathrm{~B}]}{d t} & =+k^{-}[\mathrm{BCa}]-k^{+}[\mathrm{B}]\left[\mathrm{Ca}^{2+}\right]
\end{aligned}
$$

where $\mathrm{k}^{-}$and $\mathrm{k}^{+}$are the forward and reverse rate constants for the buffer $\mathrm{B}, \mathrm{P}\left(\left[\mathrm{Ca}^{2+}\right]\right)$ is the calcium-level dependent rate of calcium extrusion, and $\mathrm{L}$ is a constant calcium influx (leak). $\mathrm{P}\left(\left[\mathrm{Ca}^{2+}\right]\right)$ was modeled as a first-order reaction [see Eq. (13)]. L was set equal to the extrusion rate at a resting $\left[\mathrm{Ca}^{2+}\right]$ level [see Fq. (38)]. Fxcept where noted in the text, we assumed $k^{+}=10^{8}(\mathrm{M} \mathrm{sec})^{-1}$, with $k^{-}=\mathrm{K}_{\mathrm{B}} / k^{+}$. The values used for the other parameters are indicated in the figure captions.

In a few test simulations we did not assume spatial homogeneity and examined the effects of diffusion in a multicompartment model in which the terminal was comprised of 10 spherical shell conpartments. Reaction kinetics similar to that shown above were employed in each compartment, with only the outer shell containing the leak and pump. In addition, the chemical species $\mathrm{Ca}^{2+}, \mathrm{B}$, and $\mathrm{BCa}$ were assumed to be freely diffusing and the radial diffusion equation was numerically in- 
tegrated as detailed in (Sala and Hernandez-Cruz, 1990). Fxcept where noted in the text, there was no significant difference in the $\left[\mathrm{Ca}^{2+}\right] \mathrm{dy}$ namics examined in this study between the single compartment model and the multicompartment shell model.

\section{Results}

Characteristics of $\left[\mathrm{Ca}^{2+}\right]$ buildup and decay in presynaptic nerve terminals

A set of curves showing the buildup and decay of fura-2-measured $\left[\mathrm{Ca}^{2+}\right]$ in nerve terminals of the crayfish opener muscle are shown in Figure 1. The different curves represent different concentrations of the exogenous calcium buffer fura-2, which was also the fluorescence indicator used to measure $\left[\mathrm{Ca}^{2+}\right]$ changes. Increasing concentrations of fura- 2 were produced by sequential bolus iontophoretic microinjections into the supporting axon. The fura- 2 levels in the terminals after equilibration of each bolus were estimated from the fluorescence intensity prior to stimulation (see Materials and Methods). $\left[\mathrm{Ca}^{2+}\right]$ buildup was produced by stimulating the nerve with a constant frequency train of suprathreshold brief current pulses through a suction electrode. The same train frequency-and thus the same $\left[\mathrm{Ca}^{2+}\right]$ load per unit time-was used at each fura- 2 concentration.

The plateau level reached during the action potential train did not depend on the concentration of exogenous calcium buffer. Conversely, the kinetics of the buildup and decay were dramatically altered: increasing exogenous buffer concentration slowed both the buildup and the decay. Because the plateau phase (below $25 \mathrm{~Hz}$ stimulation) could be maintained for long periods of time, it must be a steady-state situation in which the net calcium influx per unit time equals net efflux. This is consistent with the expectation that calcium buffers should only alter the rates at which $\left[\mathrm{Ca}^{2+}\right]$ levels change, not steady-state levels.

A second characteristic feature of the data in Figure 1 is that the decays were not exponential at the high levels immediately following the train, but did closely approximate exponential behavior (the curves approach straight lines on the semi-log plot) below about $500 \mu \mathrm{M}$. The characteristic decay time of the exponential phase became longer with increasing buffer concentration.

A third characteristic feature was that following termination of the action potential train, $\left[\mathrm{Ca}^{2+}\right]$ dropped smoothly over the first few data points. Particularly at the higher fura- 2 concentrations it is evident that the decay can be smoothly extrapolated back to the level reached at the last time point during the train. This is consistent with the idea (see (Delaney and Tank, 1994) that during the stimulus train, the $\left[\mathrm{Ca}^{2+}\right]$ levels determined from fura-2 fluorescence represent spatially averaged $\left[\mathrm{Ca}^{2+}\right]$ in the terminal, with negligible effects produced by high-concentration, rapid (msec), localized transients that are expected near open calcium channels during each action potential (see, for example, Llinas et al., 1992). Note that the $\left[\mathrm{Ca}^{2+}\right]$ change that is reported by our measurements for a single action potential is only a few nM (see Fig. 6A) and thus although increases in total fluorescence from a structure containing a high-affinity indicator can be produced as calcium ions diffuse away from microdomains, this effect would be expected to be small in the experiments described here

Figure 2 provides evidence that the deviations from single exponential decay in Figure 1 (particularly evident with high exogenous buffer concentrations) become more pronounced at higher $\left[\mathrm{Ca}^{2+}\right]$ levels. Presynaptic terminals were loaded with fura-2 to a level of approximately $900 \mu \mathrm{M}$, providing a limiting
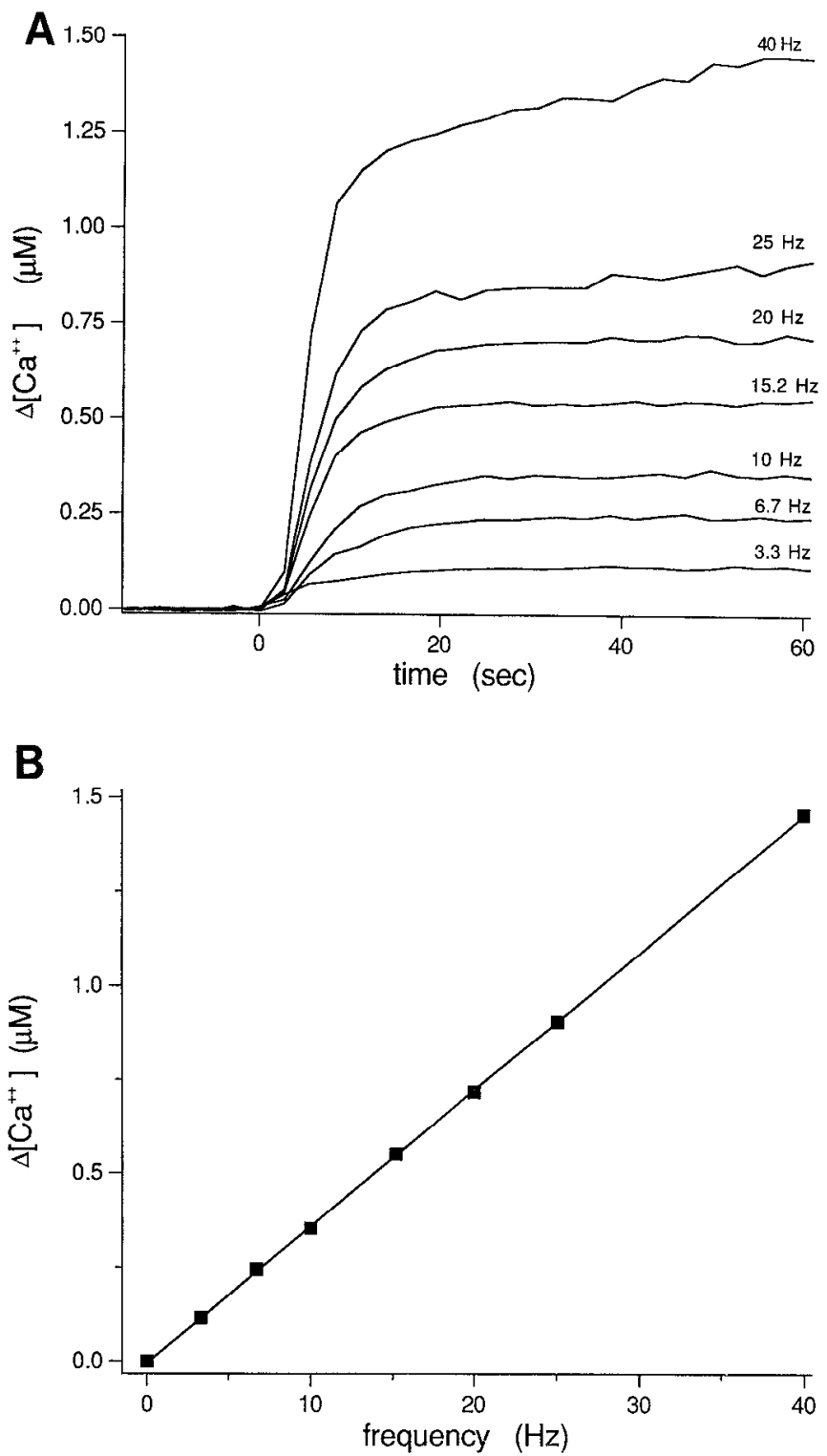

Figure 3. The dependence of steady-state plateau level of $\Delta\left[\mathrm{Ca}^{2+}\right]$ on the frequency of action potential trains in crayfish presynaptic terminals filled with a moderate $(\approx 700 \mu \mathrm{m})$ concentration of fura-2. A, Buildup of intracellular $\left[\mathrm{Ca}^{2+}\right]$ to plateau levels for the frequencies of action potential trains indicated. $B$, A graph of the steady-state $\left[\mathrm{Ca}^{2+}\right]$ level reached during the last $5 \mathrm{sec}$ of stimulus trains as a function of action potential frequency. The data is well fit by a linear function.

exponential decay time of about $20 \mathrm{sec}$. The frequency of the action potential train was varied to produce three different initial $\left[\mathrm{Ca}^{2+}\right]$ levels $\mathrm{Ca}^{0}$. All three curves show the same exponential decay for low $\left[\mathrm{Ca}^{2+}\right]$. In contrast, the decay from $\mathrm{Ca}^{0}=1.6 \mu \mathrm{M}$ cannot be approximated by a single exponential. Thus, the presence of nonexponential decay primarily reflects the level of $\left[\mathrm{Ca}^{2+}\right]$ obtained during the stimulus train, and is not a consequence of the aftereffects of the train itself.

The effects of exogenous buffer concentration shown in Figures 1 and 2 were independent of the fact that fura-2 was also being used to measure $\left[\mathrm{Ca}^{2+}\right]$. Similar results were observed when fura- 2 concentrations were relatively low $(\sim 200 \mu \mathrm{M})$ but combined with high concentrations of other nonfluorescent calcium buffers like EDTA and EGTA (Delaney and Tank, 1994). 

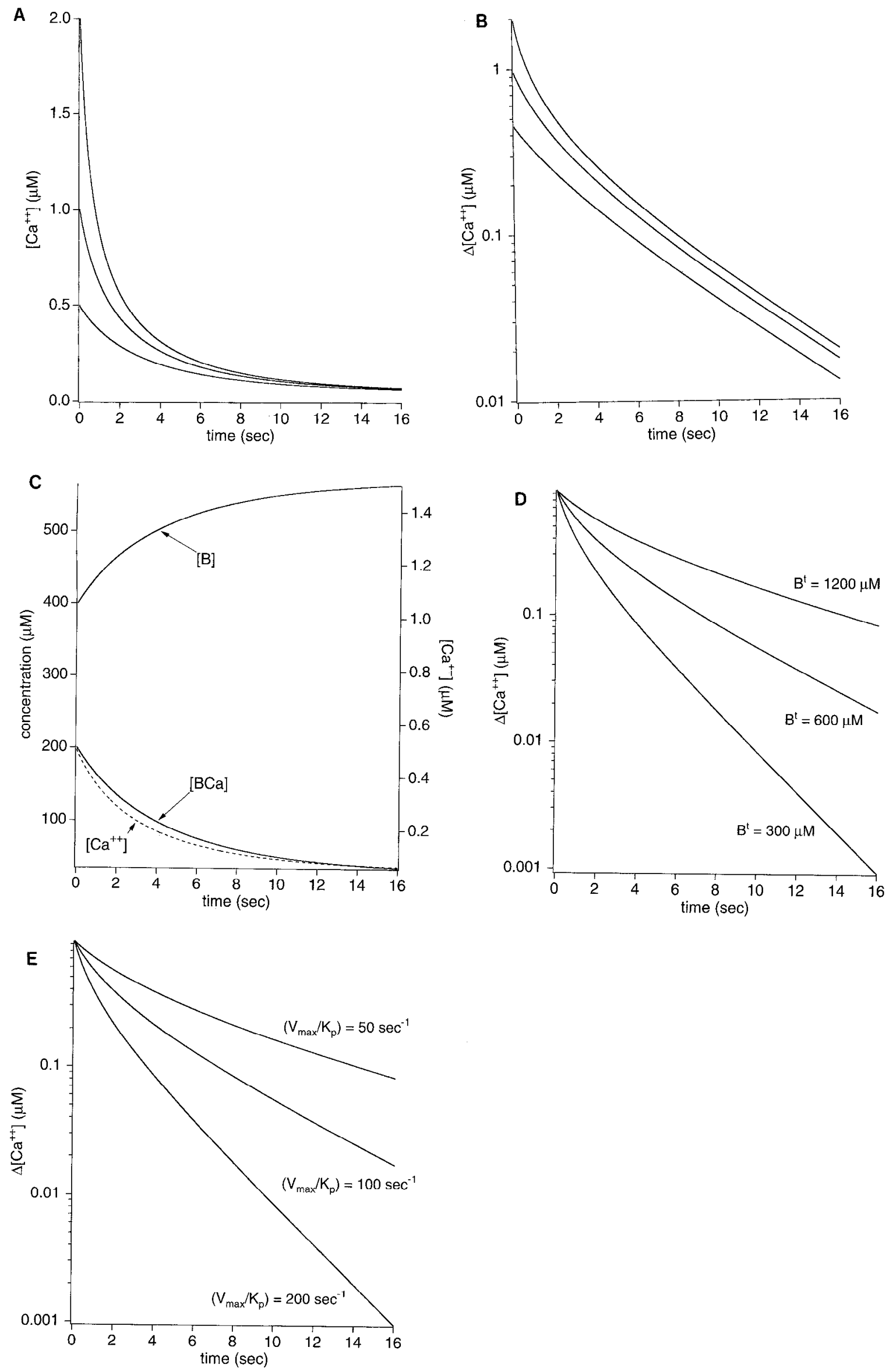
Experimental evidence for an extrusion mechanism linear in $\left[\mathrm{Ca}^{2+}\right]$

The buildup and plateau of presynaptic terminal $\left[\mathrm{Ca}^{2+}\right]$ for stimulus trains of different action potential frequency is shown in Figure $3 A$. As shown in Figure $3 B$, we found that the level of $\left[\mathrm{Ca}^{2+}\right]$ during the plateau (Caplateau; measured $60 \mathrm{sec}$ after start of the train) produced by a train was a linear function of the action potential frequency $(f)$ :

$$
\text { Ca } a^{\text {plateau }} \propto f \text {. }
$$

We also found that the shape of action potentials measured in the preterminal axon does not appreciably change for short trains of action potentials in the frequency range below $25 \mathrm{~Hz}$. This suggests that, within this limited range of frequency and train duration, the calcium influx per action potential is constant and thus the net rate of calcium influx during a train is a linear function of the action potential frequency. As derived in Appen$\operatorname{dix} A$, the fact that the plateau level is a linear function of frequency and the influx at that level is also a linear function of frequency implies that the calcium removal rate $\left[\mathrm{P}\left(\left[\mathrm{Ca}^{2+}\right]\right)\right]$ is a linear function of $\left[\mathrm{Ca}^{2+}\right]$ :

$$
\mathrm{P}\left(\left[\mathrm{Ca}^{2+}\right]\right) \propto\left[\mathrm{Ca}^{2+}\right] .
$$

Previous investigators (Sala and Hernandez-Cruz, 1990) modeled calcium extrusion using a first order Michaelis-Menten formulation for a calcium pump:

$$
\begin{aligned}
\mathrm{P}\left(\left[\mathrm{Ca}^{2+}\right]\right) & =\frac{V_{\max }\left[\mathrm{Ca}^{2+}\right]}{\left(\left[\mathrm{Ca}^{2+}\right]+K_{p}\right)}, \\
V_{\max } & =\frac{v_{\max } A}{V},
\end{aligned}
$$

where $v_{\max }$ is the efflux rate per unit area of cell membrane (units: $\mathrm{mol} / \mathrm{cm}^{2} \mathrm{sec}$ ), $A$ is the terminal surface area, $V$ is the terminal volume, and $K_{p}$ is the half-maximal concentration (Michaelis constant). Our data do not distinguish between a calcium pump and other extrusion mechanisms such as $\mathrm{Na}^{+} / \mathrm{Ca}^{2+}$ exchange. However, our results are consistent with the expression in Eq. (11) in the limiting case that the $\left[\mathrm{Ca}^{2+}\right]$ levels of interest are small compared to $K_{p}\left(\left[\mathrm{Ca}^{2+}\right\rfloor \ll K_{p}\right)$, in which case Eq. (11) reduces to

$$
\mathrm{P}\left(\left[\mathrm{Ca}^{2+}\right]\right)=\frac{V_{\max }\left[\mathrm{Ca}^{2+}\right]}{K_{p}} .
$$

For consistency with previous work, we will use this form in our model. In Eqs. (11) and (13), the removal rate has been scaled by the size of the terminal and has units of (concentration/ time).

\section{A single compartment model of $\left[\mathrm{Ca}^{2+}\right]$ decay}

The slow decay times evident in the data in Figures 1 and 2 imply that spatial $\left[\mathrm{Ca}^{2+}\right]$ gradients are small during the decay phase, and a single compartment model that ignores diffusion is an appropriate description. The effects shown in these figures are easily accounted for in a single compartment model that uses a calcium extrusion process linear in $\left[\mathrm{Ca}^{2+}\right]$. The easiest model to understand assumes that the compartment is filled with a single calcium buffer $\mathbf{B}$ of total concentration $\mathbf{B}^{t}=[\mathbf{B}]+[\mathrm{BCa}]$, where $[\mathrm{B}]$ is the concentration of free buffer and $[\mathrm{BCa}]$ is the concentration of buffer with bound calcium ion. $\mathrm{B}$ is assumed to be a simple first-order buffer,

$$
\mathrm{B}+\mathrm{Ca} \underset{k^{-}}{\stackrel{k^{+}}{\rightleftarrows}} \mathrm{BCa},
$$

characterized by forward and reverse rate constants $\left(k^{+}, k^{-}\right)$and a corresponding equilibrium dissociation constant $K_{B}=\left(k^{-} / k^{+}\right)$.

$\left[\mathrm{Ca}^{?+}\right]$ decay simulation was produced by assuming an initial steady-state $\left[\mathrm{Ca}^{2+}\right]$ level $\mathrm{Ca}^{0}$ in equilibrium with $\mathrm{B}$ and then numerically integrating the differential equations (see Materials and Methods section) describing the rate of change of $\left[\mathrm{Ca}^{2+}\right]$, free buffer, and calcium-bound buffer. A typical time course of $\left[\mathrm{Ca}^{2+}\right]$ decay produced by the model is shown in Figure $4 A$. Three different initial starting conditions are shown: $\mathrm{Ca}^{0}=2$ $K_{B}, K_{B}$, and $0.5 K_{B}$. The decay curves in Figure $4 A$ are shown on semi-logarithmic axes in Figure $4 B$. At low $\left[\mathrm{Ca}^{2+}\right]$ the decay curves are approximated by straight lines, implying that the decays at low $\left[\mathrm{Ca}^{2+}\right]$ are approximately exponential. At early time points, the shape of the decay is dependent on the initial starting concentration. Of particular note is the pronounced curvature for levels at or above $K_{B}$. Figure $4 C$ demonstrates that as the decay in $\left[\mathrm{Ca}^{2+}\right]$ proceeds, there is a concomitant decay in the concentration of bound buffer $([\mathrm{BCa}])$ and a rise in the concentration of unbound buffer $([\mathrm{B}])$. The rate of decay of $[\mathrm{BCa}]$ is very close to the rate of decay of $\left[\mathrm{Ca}^{2+}\right]$ (dashed line).

The single compartment model can be explicitly solved under the assumption that the rate of calcium equilibration with calcium buffers is fast compared to the characteristic decay times of $\left[\mathrm{Ca}^{2+}\right]$, implying that the buffer is always in chemical equilibrium. As derived in Appendix B, the model then predicts that for $\left[\mathrm{Ca}^{2+}\right]$ levels well below the equilibrium dissociation constant of the calcium buffer, the decay is approximately exponential with time constant

$$
\tau=\frac{\mathrm{B}^{t}}{K_{B}\left(V_{\max } / K_{p}\right)} .
$$

This expression states that the time constant of decay will increase linearly with increasing $\mathrm{B}^{\prime} / K_{B}$, which is the calcium buffer capacity at low $\left[\mathrm{Ca}^{2+}\right]$ levels. The decay will also be reduced inversely with increasing rate of calcium extrusion $\left(V_{\max } / K_{p}\right)$. The expected dependence of the limiting exponential decay time, at low $\left[\mathrm{Ca}^{2+}\right]$, on total butfer concentration $\mathrm{B}^{t}$ is demonstrated in the computer simulations in Figure $4 D$. Similarly, the inverse scaling of decay time with $V_{\max } / K_{p}$ is demonstrated in the computer simulations shown in Figure $4 E$.

For $\left[\mathrm{Ca}^{2+}\right]$ levels approaching and exceeding $K_{B}$ the decay

$\leftarrow$

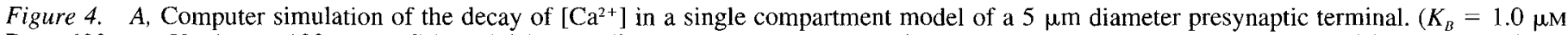

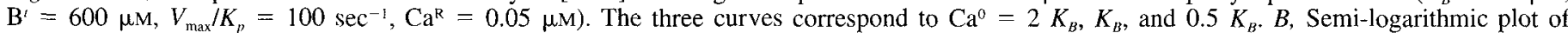

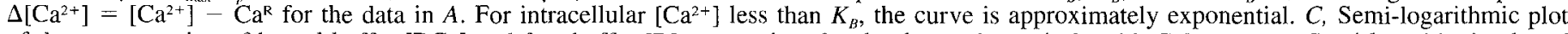

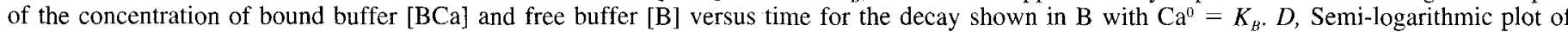

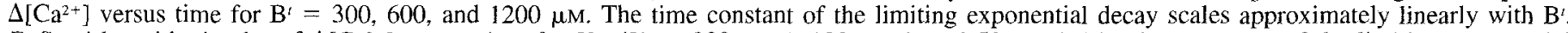

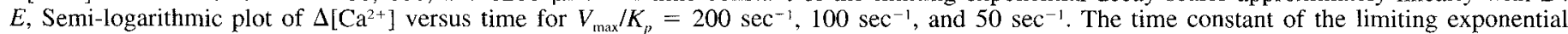
decay scales inversely with the extrusion rate. 
will be faster. From Eq. (42) in Appendix B we sec that in the $\left(\mathrm{B}^{+} \gg K_{B}\right)$ limit for $\left[\mathrm{Ca}^{2+}\right]=K_{B}$,

$$
\frac{\left(\frac{d\left(\Delta\left[\mathrm{Ca}^{2+}\right]\right)}{d t}\right)}{\Delta\left[\mathrm{Ca}^{2+}\right]}=-\frac{4 K_{R} V_{\max }}{\mathrm{B}^{t} K_{p}},
$$

which is four times the limiting value obtained during the exponential decay phase. The exponential limit for low $\left[\mathrm{Ca}^{2+}\right]$ and the increased slope as $\left[\mathrm{Ca}^{2+}\right]$ approaches $K_{B}$ is observed in the computer simulations shown in Figure $4 B$. The three curves correspond to the three initial starting conditions $\mathrm{Ca}^{0}=0.5 K_{B}, K_{B}$, and $2 K_{B}$, with $K_{B}=1.0 \mu \mathrm{M}, \mathrm{B}^{t}=600 \mu \mathrm{M}$.

We expect that when fura- 2 is present at high concentrations, as in Figure 2, the simple model we have just described applies, with fura- 2 being the only buffer that needs to be considered. For such conditions the endogenous buffer makes insignificant contributions to the $\left[\mathrm{Ca}^{2+}\right]$ dynamics. The experiment of Figure 2 allows us to test the predictions of the single compartment, single calcium buffer model. It shows increased curvature at high $\left[\mathrm{Ca}^{2+}\right]$ levels, similar to that shown in Figure $4 B$. Furthermore, consistent with Eq. (16) above, at the position where $\left(d \Delta\left[\mathrm{Ca}^{2+}\right] / d t\right) / \Delta\left[\mathrm{Ca}^{2+}\right]$ is approximately equal to four times the limiting rate, the corresponding intra-terminal $\left[\mathrm{Ca}^{2+}\right]$ value is $850 \mu \mathrm{M}$, close to the dissociation constant estimated for fura-2 in this preparation (Delaney et al., 1989).

For the experiments of Figure 1, where a wide concentration range of exogenous buffer has been used, $\left[\mathrm{Ca}^{2+}\right]$ dynamics are better described by a model with two buffers present. (This case is also appropriate to many experimental situations where the amount of calcium indicator necessary to provide a measurement of $\left[\mathrm{Ca}^{2+}\right]$ is only several hundred micromolar, but still high enough to affect the $\left[\mathrm{Ca}^{2+}\right]$ kinetics.) If two buffers $\mathrm{B}_{1}$ and $\mathrm{B}_{2}$ are present at concentrations $\mathrm{B}_{1}{ }^{t}$ and $\mathrm{B}_{2}{ }^{t}$ then an analysis similar to that presented in Appendix $B$ shows that the $\left[\mathrm{Ca}^{2+}\right]$ decay will be approximately exponential for the low $\left[\mathrm{Ca}^{2+}\right]$ conditions specified in Eqs. (43) and (44) with time constant

$$
\tau=\left\{\frac{\mathrm{B}_{1}^{t}}{K_{\mathrm{B} 1}}+\frac{\mathrm{B}_{2}^{t}}{K_{\mathrm{B} 2}}\right\} \frac{1}{\left(\frac{V_{\max }}{K_{p}}\right)}=\tau_{1}+\tau_{2} .
$$

The total decay time is simply the sum of the contributions from the two buffers.

This expression is appropriate to the experimental results shown in Figure 1, where increasing concentrations of total buffer resulted in a longer characteristic decay time during the exponential decay portion of the curve present at low $\left[\mathrm{Ca}^{2+}\right]$. The characteristic time constant versus fura- 2 concentration is shown in Figure 5 for a set of experiments similar to that shown in Figure 1. Consistent with Eq. (17), there is a linear relationship between exogenous fura- 2 concentration and the characteristic decay time. Rearranging Eq. (17), with $\mathrm{B}_{1}=\mathrm{B}$ (endogenous buffer), $\mathrm{B}_{2}=$ fura- 2 , and $K_{F}=$ dissociation constant of fura-2, we expect that

$$
\begin{aligned}
\tau & =a_{1}[\text { fura2 }]+a_{0} \\
a_{1} & =\frac{K_{p}}{V_{\max } K_{F}} \\
a_{0} & =\frac{\mathrm{B}^{t} K_{p}}{K_{B} V_{\max }}
\end{aligned}
$$

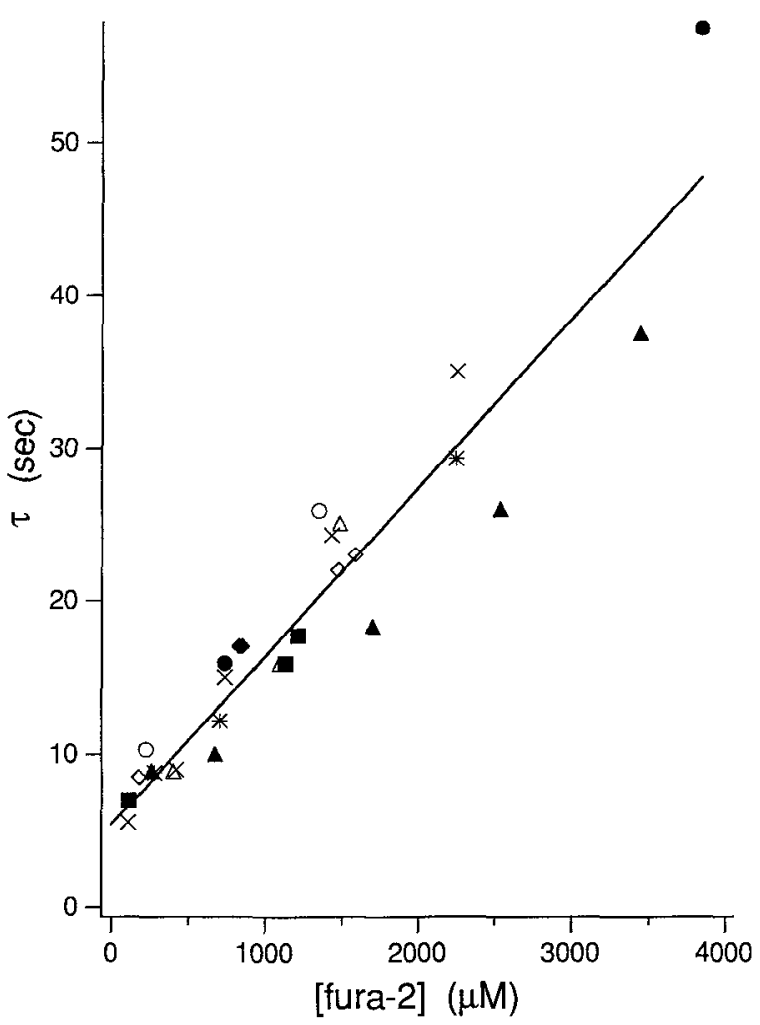

Figure 5. Graph of the characteristic decay time $(\tau)$ measured from the exponential decays at low $\left[\mathrm{Ca}^{2+}\right]$ versus the estimated intraterminal fura- 2 concentration for the data in Figure 1 and pooled data from other similar experiments. Data is from eight preparations, nine sets of terminals, with time constants averaged from responses of two to three terminals, most about $4-6 \mu \mathrm{m}$ in diameter, $T=8.5 \pm 0.5^{\circ} \mathrm{C}$. There is a linear relationship between $\tau$ and [fura-2]. The extrapolated intercept is at [fura-2] $=0 \mu \mathrm{M}$ is $\tau=5.4 \mathrm{sec}$.

These equations can be used with the experimental data to provide estimates of the extrusion process and endogenous buffer. For example, the calcium extrusion rate constant in the presynaptic terminals can be estimated from the slope $\left(a_{1}\right)$ of the data shown in Figure 5, since the equilibrium constant of fura- 2 is known:

$$
\frac{V_{\text {max }}}{K_{p}}=\frac{1}{K_{F} a_{1}}=\frac{1}{(.86 \mu \mathrm{M})\left(.011 \mathrm{sec} \cdot \mu \mathrm{M}^{-1}\right)} \approx 100 \mathrm{sec}^{-1}
$$

$\mathrm{B}^{t} / K_{B}$ for the endogenous buffer can be estimated from the slope $\left(a_{1}\right)$ and intercept $\left(a_{0}\right)$ :

$$
\frac{\mathrm{B}^{t}}{K_{B}}=\frac{a_{0}}{a_{1} K_{F}}=\frac{(5.4 \mathrm{sec})}{\left(.011 s \cdot \mu \mathrm{M}^{-1}\right)(.86 \mu \mathrm{M})} \approx 600 .
$$

The buffer capacity that corresponds to a ratio $\mathrm{B}^{t} / K_{B}=600$ would, for example, be provided by $600 \mu \mathrm{M}$ of an endogenous buffer with $K_{B}=1 \mu \mathrm{M}$. If the endogenous buffer had the same dissociation constant as fura- 2 in crayfish $(0.86 \mu \mathrm{M})$, its concentration would be $\approx 520 \mu \mathrm{M}$.

\section{Modeling $\left[\mathrm{Ca}^{2+}\right]$ buildup produced by action potential trains}

An analysis similar to that presented above for the decay of $\left[\mathrm{Ca}^{2+}\right]$ can also be applied to the buildup of $\left[\mathrm{Ca}^{2+}\right]$ produced by a train of action potentials. When the intracellular buffer characteristics are known, for example when intracellular calcium buffering is dominated by a large known amount of an exoge- 

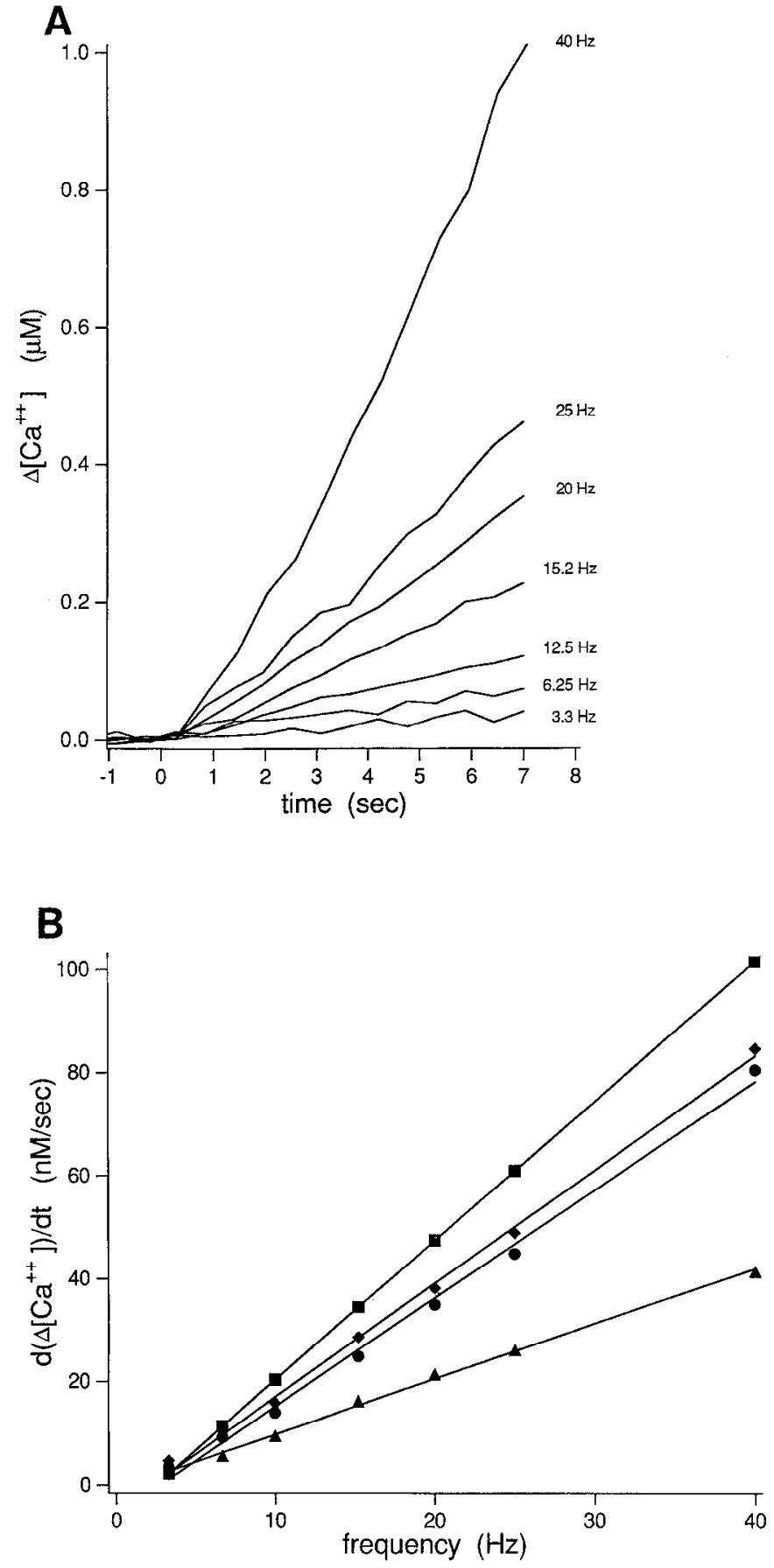

Figure 6. The dependence of the initial rate of change (slope) of $\left[\mathrm{Ca}^{2+}\right]$ on the frequency of action potential trains in crayfish presynaptic terminals filled with a high concentration of fura-2, estimated to be 2.0 mM. $A$, Time course of the buildup of $\Delta\left[\mathrm{Ca}^{2+}\right]=\left[\mathrm{Ca}^{2+}\right]-\mathrm{Ca}^{\mathrm{R}}$ for the frequencies of action potential trains indicated, in a terminal $\approx 3.5 \mu \mathrm{m}$ in diameter. The initial slope increases with increasing frequency. $B, A$ graph of the initial slope $\left(d \Delta\left[\mathrm{Ca}^{2+}\right] / d t=d\left[\mathrm{Ca}^{2+}\right] / d t\right)$ as a function of action potential frequency for $\left[\mathrm{Ca}^{2+}\right]$ buildups as in $A$ in four different terminals. For each terminal, the data is well fit by a linear function. The slope of the relationship can be used to estimate the calcium influx per action potential (see text).

nous buffer like fura-2, the rate of rise and plateau level reached during a train provide information about the calcium influx per action potential and the calcium extrusion process.

In the experiment shown in Figure $6 A$, a crayfish presynaptic terminal was filled with an estimated $2.0 \mathrm{~mm}$ fura-2. Then the buildup of $\left[\mathrm{Ca}^{2+}\right]$ in response to trains of action potentials was measured as a function of frequency. As shown in Figure $6 B$, the initial rate of change of $\left[\mathrm{Ca}^{2+}\right]$ (the initial slopes of the curves in Fig. 6A) was linearly dependent on the action potential frequency.

The linear dependence of the initial rate of $\left[\mathrm{Ca}^{2+}\right]$ rise with action potential frequency can be predicted by a simple mathematical model. At the resting $\left[\mathrm{Ca}^{2+}\right]$ level present before the onset of the stimulus train, calcium influx ( $\mathrm{L}=$ leak) and calcium efflux $\left(\mathrm{P}\left(\left[\mathrm{Ca}^{2+}\right]\right)\right.$ are equal, and

$$
\frac{d \mathrm{Ca}^{\prime}}{d t}=L-P\left(\left[\mathrm{Ca}^{2+}\right]\right)=0
$$

where $\mathrm{Ca}^{t}$ is the total calcium concentration, consisting of $\left[\mathrm{Ca}^{2+}\right]$ and calcium bound to buffer [see Eq. (37) in Appendix B]. As the train commences the pump and leak rate are still equal and cancel but there is a change $\left(f_{S} / V\right)$ in the rate of change of total calcium concentration, where $f$ is the frequency of action potential stimulation, $s$ is the calcium influx per action potential (units: moles of calcium), and $V$ is the terminal volume:

$$
\left(\frac{d \mathrm{Ca}^{t}}{d t}\right)_{\text {initial }}=\frac{1}{V}(f s) .
$$

Using a similar development to that used in Appendix B, this can be expressed as

$$
\begin{aligned}
\left(\frac{d \Delta\left[\mathrm{Ca}^{2+}\right]}{d t}\right)_{\text {initial }} & =a_{1} f \\
a_{1} & =\frac{s}{V\left\{1+\left(K_{B} \mathrm{~B}^{\prime}\right) /\left(\left[\mathrm{Ca}^{2+}\right]+K_{B}\right)^{2}\right.} .
\end{aligned}
$$

Thus, there is a linear dependence of the initial slope of $\left[\mathrm{Ca}^{2+}\right]$ versus time on the frequency of action potential stimulation. The slope of a graph of $d\left[\mathrm{Ca}^{2+}\right] / d t$ (equal to $d \Delta\left[\mathrm{Ca}^{2+}\right] / d t$ ) as a function of frequency provides a measure of $s$, the calcium influx per action potential, since the volume $V$, resting $\left[\mathrm{Ca}^{2+}\right]$ level $\left[\mathrm{Ca}^{2+}\right]=\mathrm{Ca}^{\mathrm{R}}, \mathrm{B}^{t}$, and $K_{B}$ are known when the intracellular buffer characteristics are determined by an excess of an exogenous buffer. Note that there is no explicit assumption made of the dependence of the extrusion rate on the $\left[\mathrm{Ca}^{2+}\right]$ level because the leak and pump rate cancel out at the resting $\left[\mathrm{Ca}^{2+}\right]$ level that corresponds to the initial slope measurement.

Using the expression for the slope $\left(a_{1}\right)$ inferred from Eq. (26) on the data in Figure $6 B$ provides an experimental estimate of $s$. The average of $s$ from the four different lines (four different sized terminals) is $s=2.4 \times 10^{-18} \mathrm{~mol}$ per action potential (range: $0.9-4.8$ ). To get a feeling for the magnitude of this influx per action potential, assume that the calcium current following an action potential lasts $1 \mathrm{msec}$. The calcium influx $s$ calculated above would then correspond to $460 \mathrm{pA}$ (range: 180-920) of calcium current lasting $1 \mathrm{msec}$, thus equivalent to the opcning of about 900 calcium channels, assuming a single channel calcium current of $0.5 \mathrm{pA}$ found in an invertebrate neuron (Hille, 1992) as a rough estimate of channel current.

We can use the value of $s$ determined above with the data in Figure $3 B$ showing the plateau level as a function of frequency to provide quantitative information about the rate of calcium extrusion. As previously described, at the steady state $\left[\mathrm{Ca}^{2+}\right.$ ] plateau level (Ca $\left.{ }^{\text {plateau }}\right)$ reached during a long action potential 
train at frequency $f$, the total calcium influx ( $f s / V)$ must equal the total calcium removal rate [Eq. (13)]:

$$
L+\frac{s f}{V}=\left(\frac{V_{\max } \mathrm{Ca}^{\text {platcaun }}}{K_{p}}\right),
$$

or, using Eq. 38,

$$
\frac{s f}{V}=\left(\frac{V_{\max } \Delta \mathrm{Ca}^{\text {platcau }}}{K_{p}}\right),
$$

with

$$
\Delta \mathrm{Ca}^{\text {plateau }}=\mathrm{Ca}^{\text {plateau }}-\mathrm{Ca}^{\mathrm{R}} .
$$

This can be rearranged to give

$$
\begin{aligned}
\Delta \mathrm{Ca}^{\text {prateau }} & =a_{1} f, \\
a_{1} & =\left(\frac{K_{p} s}{V_{\max } V}\right),
\end{aligned}
$$

expressing that the plateau $\left[\mathrm{Ca}^{2+}\right]$ level is a linear function of frequency. Equation (31) can be used with the slope $\left(a_{1}\right)$ of the data shown in Figure $3 B$ and our previous estimate of the calcium influx per action potential $(s)$ to provide an estimate the calcium extrusion rate:

$$
\frac{V_{\max }}{K_{p}}=\frac{s}{a_{1} V} \approx 80 \mathrm{sec}^{-1} .
$$

This value, calculated from the plateau level reached in response to action potential trains, is similar to the value calculated independently in an earlier section from the dependence of the $\left[\mathrm{Ca}^{2+}\right]$ decay kinetics on exogenous buffer concentration.

\section{Discussion}

A model of slow presynaptic $\left[\mathrm{Ca}^{2+}\right]$ dynamics

We presented a single-compartment model that provides a framework for understanding slow $\left[\mathrm{Ca}^{2+}\right]$ dynamics in nerve terminals. It includes an extrusion mechanism linear in $\left[\mathrm{Ca}^{2+}\right]$, one or two calcium buffers, and calcium entry through voltage-gated calcium channels. It ignores diffusion and internal calcium stores. Recause of the model's simplicity it was possible to derive explicit mathematical expressions for calcium buildup and decay rates. The substantial agreement between experimental results and the model suggests that it is an adequate description of $\left[\mathrm{Ca}^{2+}\right]$ dynamics in presynaptic nerve terminals on the seconds to minutes time scale.

There are many previous models of $\left[\mathrm{Ca}^{2+}\right]$ dynamics in neurons (Andresen et al., 1979; Gorman and Thomas, 1980; Smith and Zucker, 1980; Connor and Nikolakopoulou, 1982; Barish and Thompson, 1983; Zucker and Stockbridge, 1983; Stockbridge and Moore, 1984; Fogelson and Zucker, 1985; Simon and Llinas, 1985; Gamble and Koch, 1987; Tillotson and Nasi, 1988; Parnas et al., 1989; Holmes and Levy, 1990; Sala and Hernandez-Cruz, 1990; Blumenfeld et al., 1992; Yamada and Zucker, 1992; Winslow ct al., 1994). Thesc modcls have primarily cmphasized the importance of spatial gradients and intracellular $\left[\mathrm{Ca}^{2+}\right]$ diffusion, and were concerned with changes on the msec time scale. Because of the added complexity that results from introducing diffusion, these models could not be solved analytically. A style of modeling and experiment more similar to our approach has been applied to $\left[\mathrm{Ca}^{2+}\right]$ dynamics in ventricular Inyocytes (Mathias et al., 1990) and the cell bodies of secretory cells (Neher and Augustine, 1992). Our modeling is somewhat different, however, in that we did not assume small perturbations from rest in our derivations, and thus, we could describe effects such as the curvature in decay curves for $\left[\mathrm{Ca}^{2+}\right]$ levels near the $K_{B}$ of the dominant calcium buffer. We could take this approach because we were able to experimentally demonstrate the linear calcium dependence of the extrusion process over a wide range of $\left[\mathrm{Ca}^{2+}\right]$ levels. Our experiments also differ from those of Neher et al. (Neher and Augustine, 1992) in that we studied an intact fast chemical synapse.

In general, the mathematical expressions we derived can be interpreted as representing the fact that almost all of the total calcium ions are bound to calcium buffers, with calcium influx increasing, and calcium extrusion decreasing, the concentration of bound calcium. $\left[\mathrm{Ca}^{2+}\right.$ ] changes correspondingly, according to the equilibrium equations for the buffers (cf. Fig. 4C). Our analytical solutions are therefore strictly dependent on the assumption that the characteristic response time of the buffers in question are short compared to the rate of change of $\left[\mathrm{Ca}^{2+}\right]$. When this assumption is not valid it is necessary to take into account buffer kinetics, as we did in computer simulations. (An effect of slow buffer kinetics on the initial transient in a decay, that can be treated analytically, is presented at the end of Appendix B.)

One result of the model is that the decay of residual $\left[\mathrm{Ca}^{2+}\right]$ from an initial elevated level has the form of an exponential decay when the $\left[\mathrm{Ca}^{2+}\right]$ is low compared to the buffer equilibrium constant. The decay is more rapid for higher $\left[\mathrm{Ca}^{2+}\right]$ levels and a distinct kink occurs in the decay curve at the buffer dissociation constant $K_{B}$ (Fig. 2). High above $K_{B}$, where the buffer is saturated, rapid decay is observed since small changes in the amount of bound buffer correspond to large changes in $\left[\mathrm{Ca}^{2+}\right]$. Equation (42) demonstrates that, in general, the slope of the decay curve at all levels will scale with the total buffer concentration and will be inversely proportional to the calcium extrusion ratc.

Decay curves that have a limiting exponential dependence at low $\left[\mathrm{Ca}^{2+}\right]$ levels have heen described in a number of other experimental systems in which the assumptions of our model are probably valid, including the axon terminal release sites of Aplysia neurons (Connor et al., 1986), neuronal dendrites (Regehr and Tank, 1990), chromaffin cells (Neher and Augustine, 1992; Zhou and Neher, 1993), and forebrain neurons of the medial septum (Schneggenburger et al., 1993). Many of the decays deviate from single-exponential behavior at high $\left[\mathrm{Ca}^{2+}\right]$ levels by showing a more rapid decay. Our results suggest that this effect may be produced by buffer nonlinearities.

\section{Detecting changes in presynaptic calcium regulation}

Changes in $\left[\mathrm{Ca}^{2+}\right]$ dynamics that are expected when extrusion rate, calcium influx, or calcium buffer capacity arc modificd arc shown by representative drawings in Figure $8 A-D$. An increase in calcium influx will increase Caplateau and the initial slope of the $\left[\mathrm{Ca}^{2+}\right]$ buildup with no change in the decay time constant. In contrast, an increase in extrusion rate will reduce $\mathrm{Ca}^{\text {plateau }}$ and the decay time constant with no change in the slope of the initial buildup. Finally, an increase in buffer capacity produces no change in Caplatcau but increases the decay time while reducing the slope of the initial buildup. These curves suggest general strategies for associating an observed change in $\left[\mathrm{Ca}^{2+}\right]$ dynamics with a specific biophysical mechanism. 


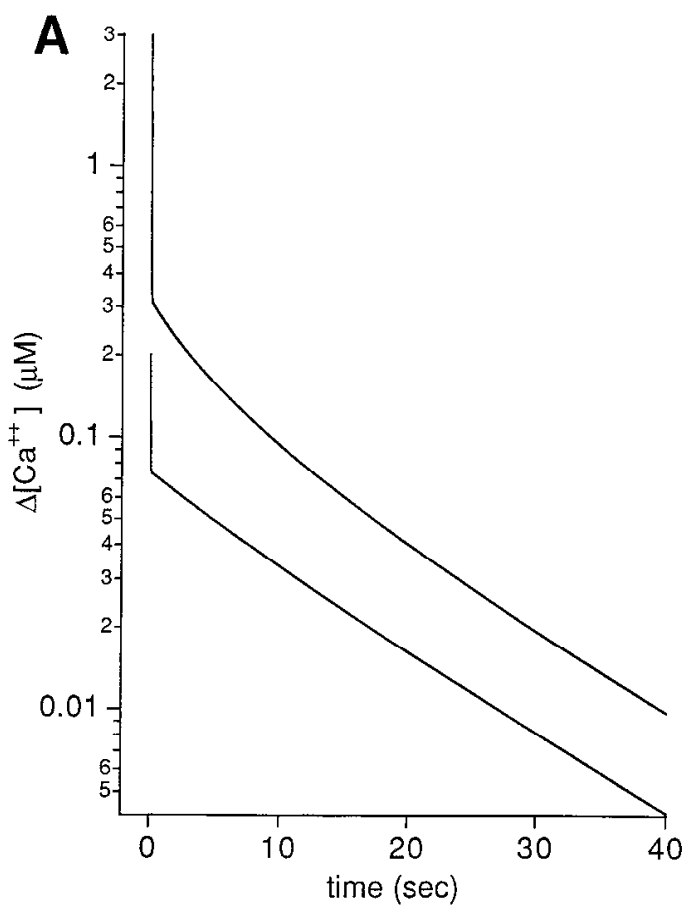

B

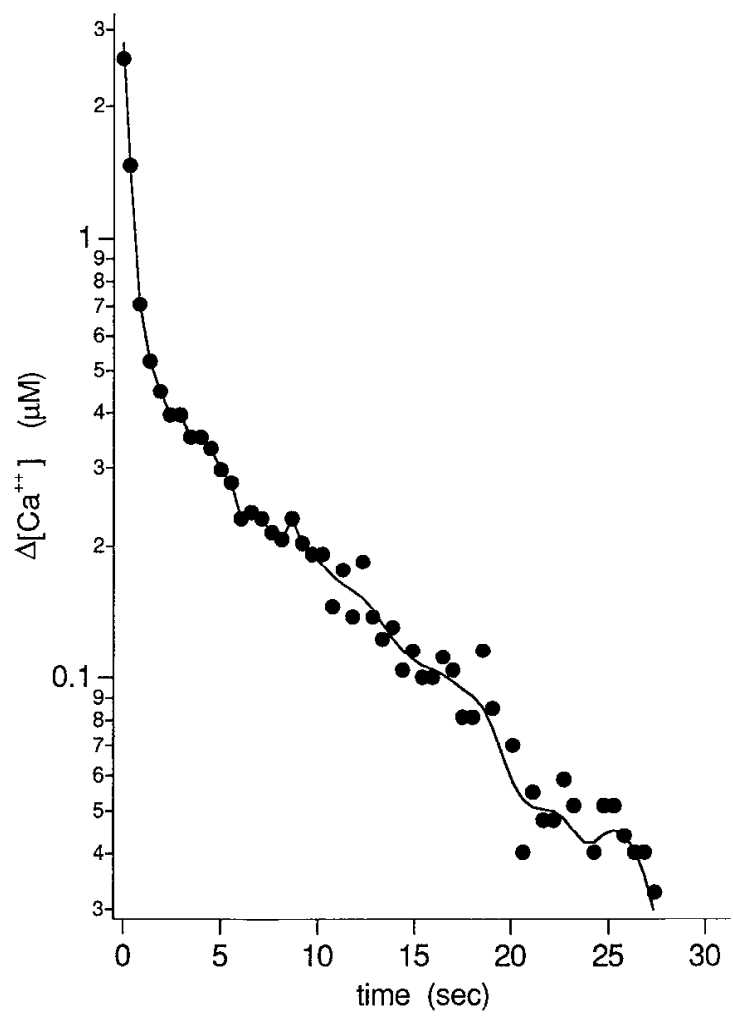

Figure 7. Fast transient decay observed for the nonequilibrium conditions when the calcium buffer binding kinetics are slow compared to the removal rate of calcium. $A$, Computer simulation of $\left[\mathrm{Ca}^{2+}\right]$ decay for $\left(K_{B}=0.8 \mu \mathrm{M}, \mathrm{B}^{t}=100 \mu \mathrm{M}, V_{\max } / K_{p}=3000 \mathrm{sec}^{-1}, \mathrm{Ca}^{\mathrm{R}}=0.15\right.$ $\mu M)$. $B$, Experimentally observed fast transient decay. A short highfrequency train was used to reach a high intracellular $\left[\mathrm{Ca}^{2+}\right]$ level without generating a large concentration of calcium bound buffer. [fura-2] $\approx 230 \mu \mathrm{M}, T=18^{\circ} \mathrm{C}$

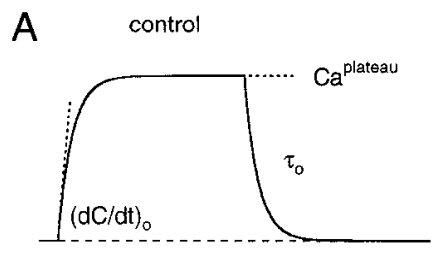

B double buffer capacity
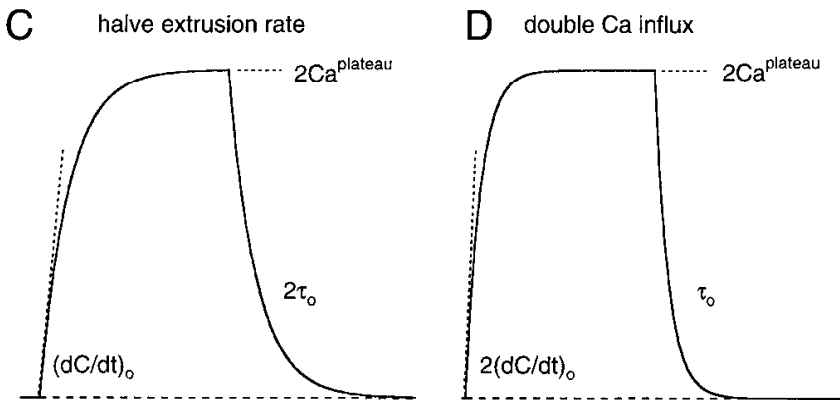

Figure 8. Illustrations of the expected changes in $\left[\mathrm{Ca}^{21}\right]$ buildup and decay produced by a calcium influx (control curve shown in $A$ ) that would be produced by doubling the buffer capacity $(B)$, reducing the extrusion rate by two $(C)$, and doubling the calcium influx per unit time during the train $(D)$. Note that these changes can be distinguished from each other because equilibrium phenomena such as plateau level are affected differently than kinetic phenomena such as decay time or initial slope of the buildup during the action potential train.

\section{Estimates of influx, buffering, and extrusion}

We used the expressions derived from the single compartment model to estimate calcium influx, buffering, and extrusion. The buffer capacity of the crayfish presynaptic terminal was estimated to be $\mathrm{B}^{\prime} / K_{B}=600$. This means that at low $\left[\mathrm{Ca}^{2+}\right]$ levels, there are about 600 bound calcium ions for each free ion. The frog sacculus contains a mobile calcium buffer that is equivalent to 800 micromolar BAPTA, and this corresponds to a much higher capacity $\left(\mathrm{B}^{t} / K_{B}=800 \mu \mathrm{M} / 0.2 \mu \mathrm{M}=4000\right.$ (Roberts, 1993)) than we observed. In contrast, chromaffin cells have a lower binding capacity, being equivalent to less that 50 micromolar fura- $2\left(\mathrm{~B}^{t} / K_{B}=50 \mu \mathrm{M} / 0.2 \mu \mathrm{M}=250\right.$; (Neher and Augustine, 1992; Zhou and Neher, 1993)). Intact salamander rod outer segments have a high-affinity mobile buffer with a buffer capacity of $\left(\mathrm{B}^{\prime} / K_{B}=240 \mu \mathrm{M} / 0.66 \mu \mathrm{M}=364\right)$ (Lagnado et al., 1992).

We demonstrated that the calcium extrusion rate was linear in $\left[\mathrm{Ca}^{2+}\right]$ and demonstrated how the proportionality constant $\left(V_{\max } d\right.$ $K_{p}$ ) for this process could be calculated by two different procedures: (1) the dependence of the buildup of $\left[\mathrm{Ca}^{2+}\right]$ from rest as a function of action potential frequency, and (2) the dependence of the time constant of $\left[\mathrm{Ca}^{2+}\right]$ decay on the concentration of exogenous buffer (fura- 2 ). Both methods gave similar values, $V_{\text {max }} / K_{p}=80-100 \mathrm{sec}^{-1}$. To our knowledge, these are the first estimates of the $\left[\mathrm{Ca}^{2+}\right]$ dependence and rate of extrusion that have been made in an intact synapse. A Na ${ }^{+} / \mathrm{Ca}^{2+}, \mathrm{K}^{+}$exchange that is activated in a first-order manner by internal free calcium, but which saturates with a mean Michaelis constant of about 1.6 $\mu \mathrm{M}$ has been observed in dialyzed outer segments of tiger salamander rods (Lagnado et al., 1992).

Our results suggest that in a single presynaptic terminal of the crayfish opener muscle the calcium influx per action potential is about $1-5 \times 10^{-18} \mathrm{~mol}$, corresponding to the influx that would be produced by about $400-20000.5 \mathrm{pA}$ calcium channels open for $1 \mathrm{msec}$. Electron micrographic studies of synaptic terminals 
of the inhibitor axon of the closer muscle indicate an average of approximately 2.4 synapses per micron in regions containing fine axon and bouton-like structures (Jahromi and Atwood, 1974). Each of these synapses has 0-4 putative release sites (mean 1.5), as determined from the presence of vesicles clustered at presynaptic dense bodies. Therefore, a reasonable estimate for the number of synapses and transmitter release sites in an average $5 \mu \mathrm{m}$ diameter inhihitor terminal is 12 and 18 , respectively. Although based on only rough estimates of channel open time and single channel current, from our measurements of the $\left[\mathrm{Ca}^{2+}\right]$ change per action potential we estimate that approximately 450 calcium channels open in response to each action potential in a $5 \mu \mathrm{m}$ terminal suggesting that there are of order 50 channels per putative release site if all channels are clustered in the membrane with vesicles at presynaptic dense bodies.

\section{Implications for short-term synaptic enhancement}

The expressions describing $\left[\mathrm{Ca}^{2+}\right]$ dynamics provide a conceptual framework for the design and interpretation of experiments on the relationship between the level of presynaptic residual $\left[\mathrm{Ca}^{2+}\right]$ and the enhancement of synaptic connection strength. For example, we have observed that the time course of synaptic augmentation follows altered $\left[\mathrm{Ca}^{2+}\right]$ kinetics produced by exogenous calcium buffers in a systematic way consistent with this model (Delaney and Tank, 1994). The direct relationship between $\left[\mathrm{Ca}^{2+}\right]$ dynamics and two forms of synaptic enhancement, augmentation, and posttetanic potentiation, suggests the hypothesis that neuromodulators could prolung or shorten the time scales of synaptic memory and thus possibly, behavioral shortterm memory, by altering calcium handling properties in presynaptic nerve terminals. Our results suggest several specific hypothesis about how such $\left[\mathrm{Ca}^{2+}\right]$ dynamics control mechanisms might work. For example, dopamine alters the kinetic properties of the ATP-dependent $\mathrm{Na}^{+} / \mathrm{K}^{+}$exchange through second-messenger/protein phosphorylation mechanisms (Bertorello et al., 1990). A similar neuromodulatory effect on the rate $\left(V_{\max } / K_{p}\right)$ of calcium extrusion in nerve terminals would alter the calcium decay rate as in Eq. (15). Changes in $\left[\mathrm{Ca}^{2+}\right]$ dynamics would also be produced by changing buffer characteristics $\left(\mathrm{B}^{\mathrm{C}}, K_{B}\right)$ through changes in transcription, translation or posttranslational alteration of binding properties.

Our model can be used as a starting point to evaluate other forms of $\left[\mathrm{Ca}^{2+}\right]$ dynamics in presynaptic terminals. For example, following high-frequency prolonged stimulation of the exciter axon in the crayfish preparation, $\left[\mathrm{Ca}^{2+}\right]$ decay acquires a second longer-time component $(60-120 \mathrm{sec})$ that is not observed in response to short low-frequency trains that only produce augmentation of synaptic transmission. This longer component of $\left[\mathrm{Ca}^{2+}\right]$ decay produces ptp. A slower decay of $\left[\mathrm{Ca}^{2+}\right]$ might be produced by a large buildup of sodium ions in the terminal reducing a sodium/calcium exchange-based calcium-extrusion mechanism. Although there is some evidence in favor of this mechanism (Mulkey and Zucker, 1992), we note that in our model slowing the extrusion rate only changes the time constant of the decay; it does not introduce a second exponential component. An additional possibility is that sequestration of calcium into internal organelles (such as mitochondria) during the train with subsequent leak into the cytoplasm during the decay may produce the longer component. This latter hypothesis seems appealing for several reasons. First, ptp becomes apparent when the frequency of action potential trains is $25 \mathrm{~Hz}$ or greater. At these frequencies, the buildup of $\left[\mathrm{Ca}^{2+}\right]$ to steady state during an action potential train acquires a slow upward creep (see Fig. 3 ) consistent with the introduction of a new (saturable) sink for $\left[\mathrm{Ca}^{2+}\right]$ ions. Second, a simple extension of the present model using a second internal calcium compartment also easily demonstrates how this mechanism could introduce an additional longer time constant component into decay kinetics.

\section{Appendix A}

Linear extrusion process from analysis of plateau levels

Once $\left[\mathrm{Ca}^{2+}\right]$ levels have plateaued during a long train of action potentials at frequency $f$, the total influx (leak + term proportional to $f$ ) and the efflux produced by the extrusion mechanism $\left(\mathrm{P}\left[\mathrm{Ca}^{2+}\right]\right)$ are balanced:

$$
\mathrm{P}\left(\mathrm{Ca}^{\text {platcau }}\right)=a_{1} f+\mathrm{L},
$$

where $a_{1}$ is a constant. The experimental observation that the plateau level is a linear function of action potential frequency also implies that

$$
\mathrm{P}\left(a_{2} f+\mathrm{Ca}^{\mathrm{R}}\right)=a_{1} f+\mathrm{L},
$$

where $a_{2}$ is a constant. Taking the derivative of both sides with respect to $f$ yields

$$
\begin{aligned}
\frac{d \mathrm{P}}{d\left[\mathrm{Ca}^{2+}\right]} a_{2} & =a_{1}, \\
\frac{d \mathrm{P}}{d\left[\mathrm{Ca}^{2+}\right]} a_{2} & =\text { constant, }
\end{aligned}
$$

with solution

$$
\mathrm{P}\left(\left[\mathrm{Ca}^{2+}\right]\right)=a_{3}\left[\mathrm{Ca}^{2+}\right],
$$

where $a_{3}$ is a constant. Although a general solution would include a constant (offset), we drop this coefficient because it would lead to the physically implausible situation of a finite pump rate at zero $\left[\mathrm{Ca}^{2+}\right]$ concentration.

\section{Appendix B}

Single compartment model analysis: kinetics of decay

Analytic expressions for decay rates can be obtained for a single compartment model. We assume that the spherical compartment is filled with a single buffer B of total concentration $\mathrm{B}^{t}$. The total calcium concentration $\mathrm{Ca}^{2}$ in the terminal is the sum of $\left[\mathrm{Ca}^{2+}\right]$ and the calcium bound to the buffer $\mathrm{B}$ :

$$
\mathrm{Ca}^{t}=\left[\mathrm{Ca}^{2+}\right]+[\mathrm{BCa}] \text {. }
$$

A resting level of calcium $\left(\mathrm{Ca}^{\mathrm{R}}\right)$ is present in nerve terminals in the absence of action potential invasion. Like the steady-state condition during the plateau phase generated by long action potential trains, in the resting steady-state condition $\left(\left[\mathrm{Ca}^{2+}\right]=\right.$ $\mathrm{Ca}^{\mathrm{R}}$ ), the total calcium concentration does not change with time and thercforc the rcsting level of calcium extrusion, given by Eq. (11) above, is balanced by a constant calcium leak (L; units are concentration/time):

$$
\mathrm{L}=\frac{V_{\max } \mathrm{Ca}^{\mathrm{R}}}{K_{p}}
$$

In a typical experiment at the crayfish neuromuscular junction, action potential trains are used to raise $\left[\mathrm{Ca}^{2+}\right]$ into the range 0.3-3 $\mu \mathrm{M}$. Then the action potential train is terminated and the decay of $\left[\mathrm{Ca}^{2+}\right]$ is measurcd. The form of this decay can be calculated in the one-compartment model. The total calcium ion 
concentration $\left(\mathrm{Ca}^{t}\right)$ decays according to the net calcium removal rate produced by the leak and calcium extrusion process:

$$
\frac{d \mathrm{Ca}^{t}}{d t}=\frac{d\left[\mathrm{Ca}^{2+}\right]}{d t}+\frac{d[\mathrm{BCa}]}{d t}=\mathrm{L}-\frac{V_{\max }\left[\mathrm{Ca}^{2+}\right]}{K_{p}} .
$$

A buffer will remain in equilibrium with the $\left[\mathrm{Ca}^{2+}\right]$ during the decay if its characteristic relaxation time is short compared to the $\left[\mathrm{Ca}^{2+}\right]$ decay time. In the following, we assume that this condition is satisfied and use the equilibrium buffer equations [Eqs. (13) and (14) in Materials and Methods) to express

$$
\begin{aligned}
\frac{d[\mathrm{BCa}]}{d t} & =\frac{d[\mathrm{BCa}]}{d\left[\mathrm{Ca}^{2+}\right]} \frac{d\left[\mathrm{Ca}^{2+}\right]}{d t} \\
& =\left(\frac{\mathrm{B}^{t} K_{B}}{\left(\left[\mathrm{Ca}^{2+}\right]+K_{B}\right)^{2}}\right) \frac{d\left[\mathrm{Ca}^{2+}\right]}{d t} .
\end{aligned}
$$

Combining this with Eq. (39) gives

$$
\frac{d\left[\mathrm{Ca}^{2+}\right]}{d t}=\frac{\mathrm{L}-\frac{V_{\max }\left[\mathrm{Ca}^{2+}\right]}{K_{p}}}{\left(1+\frac{\mathrm{B}^{t} K_{R}}{\left(\left[\mathrm{Ca}^{2+}\right]+K_{B}\right)^{2}}\right)} .
$$

This equation can be simplified when

$$
\begin{aligned}
{\left[\mathrm{Ca}^{2+}\right] } & \ll K_{B}, \\
K_{B} & \ll \mathrm{B}^{\prime},
\end{aligned}
$$

to yield

$$
\frac{d\left[\mathrm{Ca}^{2+}\right]}{d t}=\frac{\left(\mathrm{L}-\begin{array}{c}
V_{\max }\left[\mathrm{Ca}^{2+}\right] \\
K_{p}
\end{array}\right)}{\left(\frac{\mathrm{B}^{\prime}}{K_{B}}\right)} .
$$

Expressing $\mathrm{L}$ in terms of the resting $\left[\mathrm{Ca}^{2+}\right]$ level $\mathrm{Ca}^{\mathrm{R}}[\mathrm{Eq}$. (38)] and changing variables to $\Delta\left[\mathrm{Ca}^{2+}\right]=\left[\mathrm{Ca}^{2+}\right]-\mathrm{Ca}^{\mathrm{R}}$ gives

$$
\frac{d\left(\Delta\left[\mathrm{Ca}^{2+}\right]\right)}{d t}=-\frac{\frac{V_{\max } \Delta\left[\mathrm{Ca}^{2+}\right]}{K_{p}}}{\left(\frac{\mathrm{B}^{t}}{K_{B}}\right)}
$$

with solution

$$
\begin{aligned}
\Delta\left[\mathrm{Ca}^{2+}(t)\right] & =\Delta \mathrm{Ca}^{0} \exp \left(-\frac{t}{\tau}\right), \\
\Delta \mathrm{Ca}^{0}= & \mathrm{Ca}^{0}-\mathrm{Ca}^{\mathrm{R}}, \\
\tau & =\frac{\mathrm{B}^{t}}{K_{B}\left(\frac{V_{\text {max }}}{K_{p}}\right)} .
\end{aligned}
$$

Thus, when both $\left[\mathrm{Ca}^{2+}\right]$ ion concentration is small compared to the equilibrium constant for the buffer, and also the total buffer concentration is large compared to this equilibrium constant, we expect the raised intraterminal $\left[\mathrm{Ca}^{2+}\right]$ to decay exponentially with a time constant that is directly proportional to the total buffer concentration and inversely proportional to the equilibrium constant for the buffer and the rate of calcium removal. A further assumption in this derivation is that the calcium buffer remains in equilibrium during the slow decay process.

\section{A transient effect of slow buffer kinetics}

The above analysis assumes that during the decay phase the buffer kinetics are sufficiently fast to donate and accept ions and thus $\left[\mathrm{Ca}^{2+}\right]$ and calcium buffer remain in equilibrium. When the extrusion mechanisms have high capacity relative to the rate of calcium equilibration with internal buffers, this situation is violated and a sharp drop in calcium concentration from the initial state can occur before the slower decays discussed above occur. This effect is shown as the fast transient drop at time $t=0$ in a numerically calculated $\left[\mathrm{Ca}^{2+}\right]$ decay curve in Figure $7 \AA$.

The amount of the fast drop can be approximated by comparing the extrusion rate (i.e., the calcium pump rate) to the rate at which the bound calcium can be given up by B. A fast drop occurs when

$$
\frac{V_{\max }\left[\mathrm{Ca}^{2+}\right]}{K_{p}}>k^{-}[\mathrm{BCa}] .
$$

Conversely, equilibration of the buffer with the $\left[\mathrm{Ca}^{2+}\right]$ decay will occur when the $\left[\mathrm{Ca}^{2+}\right]$ has dropped from $\mathrm{Ca}^{0}$ to the level $\mathrm{Ca}^{e}$ where

$$
\frac{V_{\max } \mathrm{Ca}^{e}}{K_{p}}=k^{-}[\mathrm{BCa}] .
$$

Since the concentration of bound calcium ([BCa]) does not change appreciably during the transient drop, we can use the predecay equilibrium conditions to simplify:

$$
\begin{aligned}
\frac{V_{\max } \mathrm{Ca}^{e}}{K_{p}} & =\frac{k^{-} \mathrm{B}^{t} \mathrm{Ca}^{0}}{\left(\mathrm{Ca}^{0}+K_{B}\right)}, \\
\mathrm{Ca}^{e} & =\frac{k^{-} \mathrm{B}^{t} \mathrm{Ca}^{0}}{\left(\mathrm{Ca}^{0}+K_{B}\right)} \frac{K_{p}}{V_{\max }},
\end{aligned}
$$

or

$$
\frac{\Delta \mathrm{Ca}^{\text {fast }}}{\mathrm{Ca}^{0}}=\frac{\mathrm{Ca}^{0}-\mathrm{Ca}^{e}}{\mathrm{Ca}^{0}}=\left\{1-\frac{k^{-} \mathrm{B}^{t}}{\left(\mathrm{Ca}^{0}+K_{B}\right)} \frac{K_{p}}{V_{\max }}\right\} .
$$

Thus, the fast transient drop ( $\Delta \mathrm{Ca}^{\text {fast }}$ ) will be reduced as the concentration of buffer increases, the buffer off rate increases, the initial $\left[\mathrm{Ca}^{2+}\right]$ level decreases, or the effective pumping speed decreases.

Fast decay components are observed, under certain conditions, in the experimental measurements of $\left[\mathrm{Ca}^{2+}\right]$ decay in presynaptic terminals when [fura-2] is low. An example is shown in Figure $7 B$. In all cases that we haye examined, the drops were observed at $\left[\mathrm{Ca}^{2+}\right]$ levels above expected dissociation constants for the intracellular buffers. It was thus difficult to determine if the faster kinetics at the commencement of the decay was due to the higher slope expected above $K_{B}$, as in Eq. (15), or due to a nonequilibrium condition between buffer and $\left[\mathrm{Ca}^{2+}\right]$. In general, increasing fura- 2 concentration reduced the magnitude of fast drops of this kind (data not shown), although we could not obtain data accurate enough to directly test Eq. (54).

\section{References}

Andresen MC, Brown AM, Yasui S (1979) The role of diffusion in the photoresponse of an extraretinal photoreceptor of Aplysia. J Phsyiol (Lond) 287:283-301.

Augustine GJ, Neher E (1992) Neuronal $\mathrm{Ca}^{2+}$ signalling takes the local route. Curr Opin Neurobiol 2:302-307.

Barish ME, Thompson SH (1983) Calcium buffering and slow recovery kinetics of calcium-dependent outward current in molluscan neurones. J Physiol (Lond) 337:201-219. 
Bertorello AM, Hopficld JF, Aperia A, Greengard P (1990) Inhibition by dopamine of $\left(\mathrm{Na}^{+} / \mathrm{K}^{+}\right)$ATPase activity by neostriatal neurons through D1 and D2 dopamine receptor synergism. Nature 347:386388.

Blumenfeld H, Zablow L, Sabatini B (1992) Evaluation of cellular mechanisms for modulation of calcium transients using a mathematical model of fura- $2 \mathrm{Ca}^{2+}$ imaging in Aplysia sensory neurons. Biophys J 1146-1164.

Connor JA. Nikolakopoulou G (1982) Calcium diffusion and buffering in nerve cytoplasm. Lect. Math. Life Sci. 15:79-101.

Connor JA, Kretz R, Shapiro E (1986) Calcium levels measured in presynaptic neurone of Aplysia under conditions that modulate transmitter release. J Physiol (Lond) 375:625-642.

Delaney KR, Tank DW (1994) A quantitative measurement of the dependence of short-term synaptic enhancement on presynaptic residual calcium. J Neurosci 14:5885-5902.

Delaney KR, Zucker RS, Tank DW (1989) Calcium in motor nerve terminals associated with posttetanic potentiation. J Neurosci 9:35583567.

Delaney KR, Llinas R, Tank DW (1990) A slow component of facilitation is linearly related to presynaptic calcium at crayfish neuromuscular junction. Soc Neurosci Abstr 16:504.

Delaney KR, Tank DW, Zucker RS (1991) Presynaptic calcium and serotonin-mediated enhancement of transmitter release at crayfish neuromuscular junction. J Neurosci 11:2631-2643.

Delaney KR, Regehr WG, Tank DW (1991) Residual calcium and enhancement of transmitter release: evidence from invertebrate and vertebrate synapses for causality and universality. Soc Neurosci Abstr 17:577.

Fogelson AL, Zucker RS (1985) Presynaptic calcium diffusion from various arrays of single channels. Biophys J 48:1003-1017.

Gamble E, Koch C (1987) The dynamics of free calcium in dendritic spines in response to repetitive input. Science 236:1311-1315.

Gorman ALF, Thomas MV (1980) Intracellular calcium accumulation during depolarization in a molluscan neurone. J Physiol (Lond) 308: 259-285.

Grynkiewicz G, Poenie M, Tsien RY (1985) A new generation of $\mathrm{Ca}^{2+}$ indicators with greatly improved fluorescence properties. J Biol Chem 260:3440-3450.

Hille B (1992) Ionic channels of excitable membranes. Sunderland, MA: Sinauer Associates.

Holmes WR, Levy WB (1990) Insights into associative long-term potentiation from computational models of NMDA receptor-mediated calcium influx and intracellular calcium concentration changes. J Neurophysiol 63:1148-1168.

Jahromi SS, Atwood HL (1974) Three-dimensional ultrastructure of the crayfish neuromuscular apparatus. J Cell Biol 63:599-613.

Lagnado L, Cervetto L, McNaughton PA (1992) Calcium homeostasis in the outer segments of retinal rods from the tiger salamander. $J$ Physiol (Lond) 455:111-142.

Llinas R, Sugimori M, Silver RB (1992) Microdomains of high calcium concentration in a presynaptic terminal. Science 256:677-679.

Mathias RT, Cohen IS, Oliva C (1990) Limitations of the whole cell patch clamp technique in the control of intracellular concentrations. Biophys J 58:759-770.

Mulkey RM, Zucker RS (1992) Posttetanic potentiation at the crayfish neuromuscular junction is dependent on both intracellular calcium and sodium ion accumulation. J Neurosci 12:4327-4336.

Neher E, Augustine GJ (1992) Calcium gradients and buffers in bovine chromaffin cells. J Physiol (Lond) 450:273-301.

Parnas H, Hovav G, Parnas I (1989) Effect of $\mathrm{Ca}^{2+}$ diffusion on the time course of neurotransmitter release. Biophys J 55:859-874.

Regehr WG, Tank DW (1990) Postsynaptic NMDA receptor-mediated calcium accumulation in hippocampal CA1 pyramidal cell dendrites. 345:807-810.

Regehr WG, Tank DW (1991) The maintenance of LTP at hippocampal mossy fiber synapses is independent of sustained presynaptic calcium. Neuron 7:451-459.

Regehr WG, Delaney KW, Tank DW (1993) The role of presynaptic calcium in short-term enhancement at the hippocampal mossy fiber synapse. J Neurnsci 14:523-5.37.

Roberts WM (1993) Spatial calcium buffering in saccular hair cells. Nature 363:74-76.

Sala F, Hernandez-Cruz A (1990) Calcium diffusion modeling in a spherical neuron. Biophys J 57:313-324.

Schneggenburger R, Zhou Z, Konnerth A, Neher E (1993) Fractional contribution of calcium to the cation current through glutamate receptor channels. Neuron 11:133-143.

Simon SM, Llinas RR (1985) Compartmentalization of the submembrane calcium activity during calcium influx and its significance in transmitter relese. Biophys J 48:485-

Smith SJ, Zucker RS (1980) Aequorin response facilitation and intracellular calcium accumulation inmolluscan neurones. J Physiol (Lond) 300:167-196.

Stockbridge N, Moore JW (1984) Dynamics of intracellular calcium and its possible relationship to phasic transmitter release and facilitation at the frog neuromuscular junction. J Neurosci 4:803-811.

Swandula D, Hans M, Zipser K, Augustine GJ (1991) Role of residual calcium in synaptic depression and posttetanic potentiation: fast and slow calcium signaling in nerve terminals. Neuron 7:915-926.

Tank DW, Regehr WG, Delaney KR (1991) Modeling a synaptic chemical computation: the buildup and deday of presynaptic calcium. Soc Neurosci Abstr 17

Tillotson D, Nasi E (1988) $\mathrm{Ca}^{2+}$ diffusion in the cytoplasm of Aplysia neurons: its relationship to local concentration changes. In: Calcium channels and ion modulation, pp 133-146. New York: Plenum.

Winslow JL, Duffy SN, Charlton MP (1994) IIomosynaptic facilitation of transmitter release in crayfish in not affected by mobile calcium chelators: implications for the residual ionized calcium hypothesis from electrophysiological and compuational analyses. J Neurophysiol 72:1769-1793.

Yamada WM, Zucker RS (1992) Time course of transmeitter release calculated from simulations of a calcium diffusion model. Biophys $\mathbf{J}$ 7:671-682.

Zhou ZA, Neher E (1993) Mobile and immobile calcium buffers in bovine adrenal chromaffin cells. J Physiol (Lond) 469:245-273.

Zucker RS, Stockbridge N (1983) Presynaptic calcium diffusion and the time courses of transmitter release and synaptic facilitation at the squid giant synapse. J Neurosci 3:1263-1269.

Zucker RS, Delaney KR, Mulkey R, Tank DW (1991) Presynaptic calcium in transmitter release and posttetanic potentiation. In: Annals of the New York Academy of Science, Calcium entry and action at the presynaptic nerve terminal (Stanley E, Triggle J, Nowycki M, eds), pp 191-207. New York: New York Academy of Sciences. 